\title{
Research on Carbon Emission Efficiency in the Chinese Construction Industry based on a Three- stage DEA-Tobit Model
}

\section{Mengna Zhang ( $\sim$ ZMN0512@163.com)}

Nanjing University of Information Science and Technology https://orcid.org/0000-0002-0879-7902

Lianshui Li

Nanjing University of Information Science and Technology

Zhonghua Cheng

Nanjing University of Information Science and Technology

\section{Research Article}

Keywords: Construction industry, External environmental factors, Three-stage DEA, Carbon emission efficiency, Internal influencing factors, China

Posted Date: February 22nd, 2021

DOl: https://doi.org/10.21203/rs.3.rs-196554/v1

License: (c) (i) This work is licensed under a Creative Commons Attribution 4.0 International License. Read Full License 
1 Research on Carbon Emission Efficiency in the Chinese

2 Construction Industry based on a Three-stage DEA-

3 Tobit Model

4

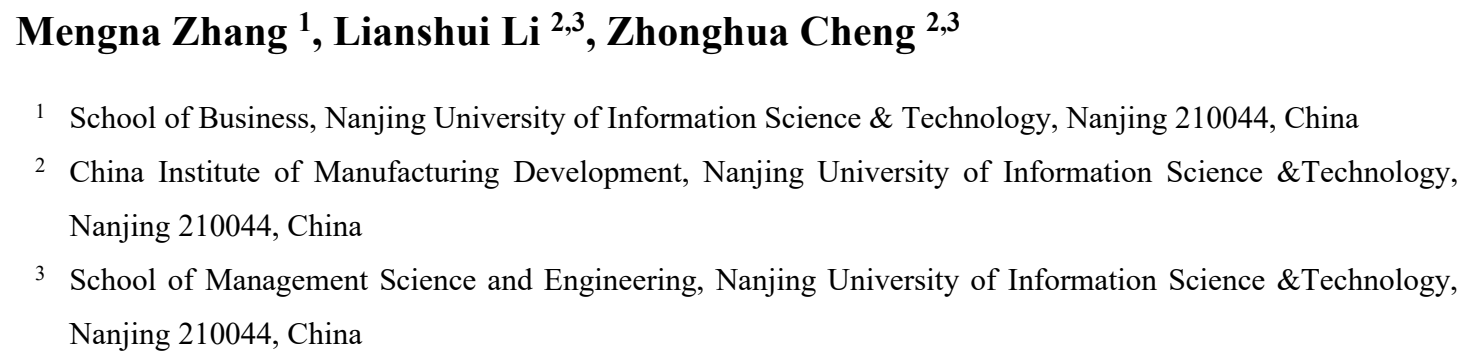

Abstract: The traditional data envelopment analysis (DEA) model usually ignores the influence of external environmental factors and random interference. This can easily lead to deviations in efficiency estimates. In order to solve this problem, a three-stage DEA model was used to better reflect the carbon emission efficiency of Chinese construction industry (CEECI) (2006-2017) from the perspective of non-management factors. The internal influencing factors of CEECI are analyzed by the Tobit model, which provides a more accurate basis for formulating policies. It is found that the CEECI is significantly affected by the GDP, the level of industrialization, the degree of opening-up, technological innovation and energy structure. After excluding environmental factors and random interference, the average CEECI increased by $16 \%$. The resulting calculations were noteworthy in three aspects. First, there are significant regional differences in the CEECI. Both the multipolarization phenomenon of CEECI and regional differences also reduced gradually over time. Second, the CEECI can be decomposed into pure carbon emission efficiency (PCEE) and scale efficiency (SE), which is mainly caused by SE. Excluding external environmental factors and random interference will have a specific impact on the CEECI. All the 30 provinces are divided into four 
categories to analyze the reasons and solutions of the differences in the CEECI in provinces. Third, many factors had inhibitory effects on the CEECI, PCEE and SE; these included energy structure optimization, labor force number, total power of construct ion equipment and construction intensity in the construction industry. Nevertheless, the development level of the construction industry did have a significant positive effect.

Keywords: Construction industry; External environmental factors; Three-stage DEA; Carbon emission efficiency; Internal influencing factors; China

\section{Introduction}

With the global warming and resource depletion, energy consumption and carbon dioxide emission efficiency are deeply concerned. According to the World Energy Statistics Review, China's energy consumption accounted for $24.3 \%$ of the global total in 2019 (Liu et al. 2020), and its total carbon dioxide emissions exceeded 10 billion tons, accounting for $30.21 \%$ of the global total emissions (Feng and Li 2020). China pledged that the intensity of carbon emissions would be reduced to just 40\%-45\% of the 2005 levels in 2030 . However, China is still in the rapid industrialization development stage, with a high and stable demand for energy consumption. In particular, technology and efficiency of energy utilization are generally lower than those of developed countries. As a result, there is increased pressure on China to reduce emissions in the international context ( $\mathrm{Li}$ and Lin 2015). Therefore, it is very essential to enhance the emission efficiency of carbon dioxide.

As a pillar industry of China's economy, the construction industry consumes more than half of the world's construction cement and steel. Base on the latest data from the National Bureau, the energy consumption of the construction industry was 8,555 ten thousand tons of standard coal, accounting for about $30 \%$ of the total energy consumption in 2017 (Huo et al. 2020). The carbon emissions from construction industry account for $30 \%-40 \%$ of the total 
carbon emissions in China (Liu et al. 2016). It far exceeded other industries such as agriculture and transportation and has become the main sector of energy consumption and carbon emissions. In addition, as the main internal driving force, the high-speed urbanization process necessitating the rapid development of China's construction industry, will result in sustained highlevel carbon emissions. Consequently, improving the CEECI has been widely regarded as the most effective way, which can reduce energy consumption and air pollutant emissions (Tan et al. 2016). Due to the important position of the construction industry in coping with energy shortages and implementing a strategy for global warming, it is crucial to accurately measure the CEECI, analyze the influencing factors and provide a more scientific basis for formulating relevant policies. It is both vital to promote the sustainable development of the construction industry and more effectively control, the carbon emissions of China.

However, the research on The CEECI is very scarce. Xue et al. (2015) used DEA-based Malmquist productivity index to measure the change of energy consumption productivity of construction industry in 26 provinces of China from 2004 to 2009. Feng and Wang (2017) used meta-frontier DEA model to study the changes of energy efficiency in China's construction industry and the reasons of low energy efficiency between 2000 and 2014. Huo et al. (2020) calculated the total-factor energy efficiency of construction industry by using the traditional DEA model from 2006 to 2015. Although the above research focuses on China's construction industry, the traditional DEA model fails to bring external environmental factors and random interfere into the model. This method ignores the heterogeneity of the external environment of China's provinces, and the value of efficiency is not real for China's construction industry. Therefore, this paper uses a three-stage DEA model. On the one hand, it can eliminate the differences in the external environment of various provinces, which can measure the real CEECI and provide reliable basis for 
policy makers; On the other hand, the regional and provincial differences in the CEECI are concerned, which is conducive to the vertical comparison and improves the carbon emission efficiency.

\section{Literature Review}

With climate and environmental problems becoming ever more serious in the world, scholars at home and abroad have been doing more and more research into carbon emission efficiency (CEE). Yamaji et al. (1993) proposed evaluating carbon productivity by using single-element indicators to estimate CEE. Since then, some scholars have used various single-element evaluation indicators to measure the CEE; these include the ratio of gross national product (GNP) to total carbon emissions, unit energy of carbon emissions and unit gross domestic product (GDP) of energy consumption (Long et al. 2016; Pretis and Roser 2017; Ferreira et al. 2018; Vujović et al. 2018). Under this analytical framework, the improvement of CEE not only depends on the potential to reduce carbon emissions, but also relies on the output capacity under the existing inputs to enhance the potential (Cheng et al. 2018). However, the single factor index only considers the impact of energy consumption on economic outputs, ignoring the internal connection with non-energy resources and other production inputs. It cannot fully reflect the multi-dimensional characteristics of CEE (Jaraite and Di Maria 2012). For the first time, Hu and Wang (2006) introduced an index of total-factor to measure the CEE of an economy. Based on a multi-input and multi-output system, they investigated the relationship between multi-factor input and output, including energy consumption, labor and capital. It made up for the drawbacks of a single index as it more accurately reflected the efficiency levels of regional economic activity and has since been widely used. Cheng et al. (2018) selected inputs, including capital, labor and energy, with the operating income of industry and carbon emissions chosen as outputs to construct the index of total-factor. This 
was used to measure the CEE of industrial sectors in China. Zhou et al. (2020) adopted labor, water, land, energy and capital investment as input indicators with waste water, sulfur emissions, industrial dust and GDP selected as output indicators; these constructed the evaluation indicators of total-factor to measure the ecological efficiency of the Chinese provinces.

How to measure the CEE of a region or industry is also hotly debated in current research. During the analysis of input-output efficiency, some scholars have adopted the stochastic frontier analysis (SFA) to quantitatively explore the influence of efficiency differences of decision-making units (DMUs). These were based on economic theories to get more accurate results with a set method model (Dong et al. 2013; Cai et al. 2019; Jin and Kim 2019; Sun and Huang 2020). However, not only does the SFA model need to be set in the form of specific functions, but the assumptions must also be relatively strict. When the model is set with inaccuracies, the results after measurement are likely to be biased. But the data envelopment analysis (DEA) does not need to set the mode of production for input factors and output factors. Instead, it objectively calculates the weight of each index based on input-output data which avoids estimation bias caused by either the wrong settings of the parameter model or subjectivity. These methods have been recognized by most scholars and have been widely applied in research including the energy efficiency (Lin and Liu 2015; Feng and Wang 2017), enterprise performance (Yan et al. 2017; Wu et al. 2018) and thermal power industry CEE (Yan et al. 2017).

The above research methods have ignored the influence of environmental factors and random interference. When the DMUs are in different external environments, using the traditional DEA model ignores the input-output slack and leads to interference by non-managerial factors. It may make different environments and luck further affect the authenticity and accuracy of the estimation results due to the difference in selection of research objects ( $\mathrm{Li}$ et al. 
2020). With this in mind, Fried et al. (2002) proposed a three-stage DEA method further based on both the SFA method and the traditional DEA model. The three-stage DEA model puts each DMU in the same environment, overcoming the influence of environmental factors and random interference, all of which makes the measurement results more exact.

At present, the three-stage DEA model had been widely applied in the manufacturing industry ( $\mathrm{Li}$ and Lin 2016), the integrated circuit industry (Li et al. 2020), the iron and steel industry ( $\mathrm{Xu}$ and Lin 2016), the transportation industry (Cui and Li 2014) and other industry. It displays the superiority and accuracy of efficiency assessment. However, the three-stage DEA model is still seldom used in the construction industry. Based on the above analysis, this paper uses the three-stage DEA method to evaluate the CEECI in 30 Chinese regions from 2006 to 2017.

\section{Materials and Methods}

\subsection{Model construction}

The three-stage DEA model was applied to calculate the input and output of non-radial slacks for DMUs, eliminating the influence of external environmental factors and random interference, which measure the CEECI more accurately. In the first stage, the input-oriented DEA-BCC model was used to calculate the CEECI under the influence of external environment and random factors. In the second stage, the SFA model was constructed by taking the slacks of inputs obtained in the first stage as explained variables and environment variables as explanatory variables. This eliminates the influence of non-management factors, including external environment and random factors, and obtains the input variables after adjustment of the construction industry in the regions. In the third stage, adjustments were made to the input variables used in the input-oriented DEA-BCC model. In this step, the CEECI was recalculated but did not include the environmental variables and the random 
171 factors, which made the efficiency values more real and accurate. Refer to

172 (Zhao et al. 2019), the analysis framework is shown in Fig. 1.

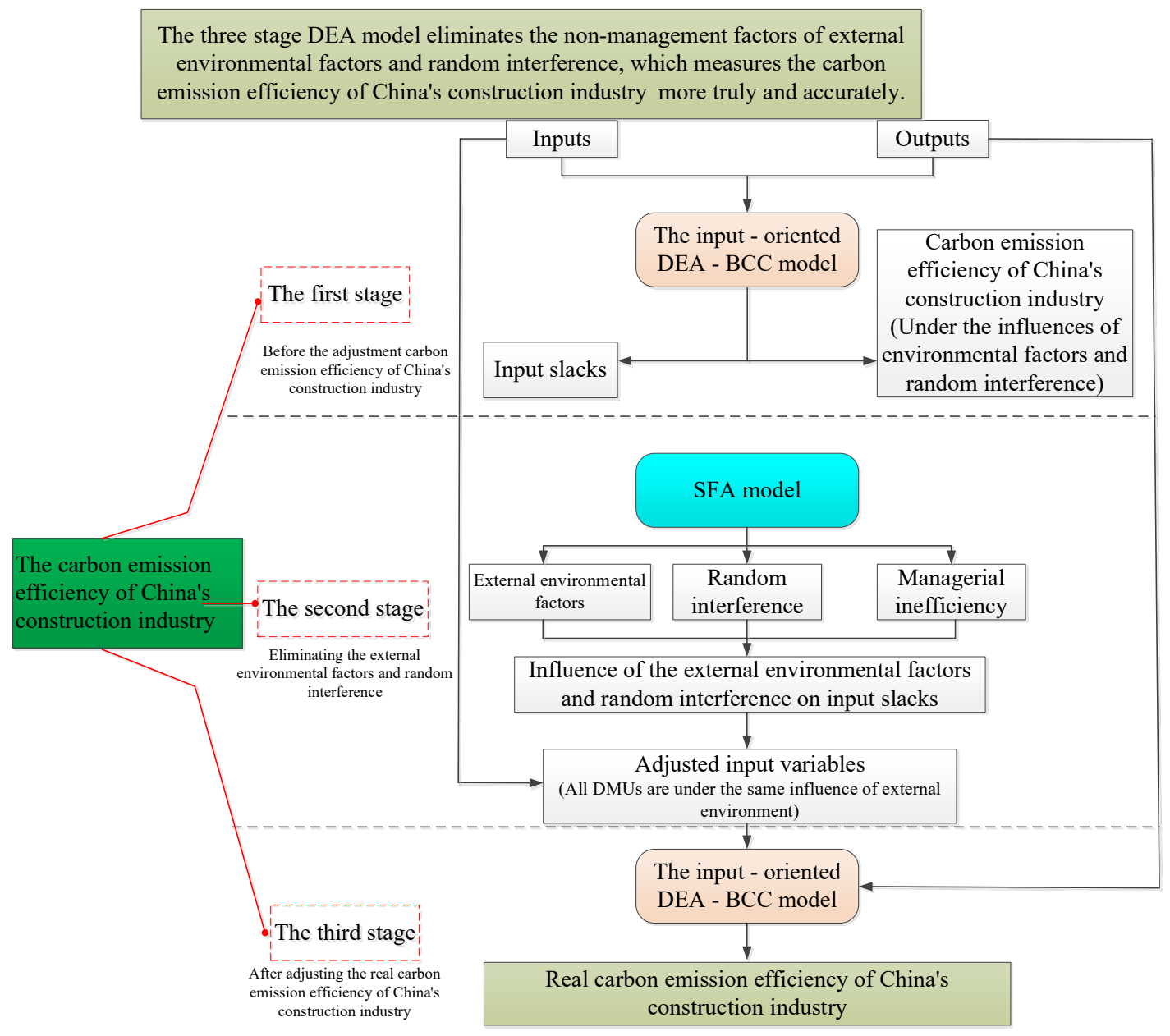

Fig. 1 Three-stage DEA model. It further decomposes the CEECI into the PCEE and SE under the hypothesis that variable returns to scale (VRS) change. Meantime, compared with the CCR model, the BCC model eliminates the influence of scale factors and evaluates the management and decision levels of DMUs more accurately. In terms of the construction industry, it is much easier to control input than output. Therefore, this paper chooses the input-oriented DEA-BCC model, as shown in Model 1:

$$
\min \left[\theta-\varepsilon\left(\sum_{j=1}^{m} S^{-}+\sum_{j=1}^{s} S^{+}\right)\right]
$$




$$
\begin{gathered}
\sum_{j=1}^{n} X_{j} \lambda_{j}+S^{-}=\theta X_{j} \\
\sum_{j=1}^{n} Y_{j} \lambda_{j}-S^{+}=Y_{j} \\
\sum_{\mathrm{j}=1}^{n} \lambda_{\mathrm{j}}=1 \\
S^{+} \geq 0, S^{-} \geq 0, \quad \lambda_{j} \geq 0, \quad 0 \leq \theta \leq 1
\end{gathered}
$$

Each province is regarded as a DMU when the CEECI is calculated. If there are $n$ provinces, denoted as $\operatorname{DMU}_{j}(j=1,2,3 \ldots \ldots n)$, each DMU has $m$ inputs and $\mathrm{n}$ outputs. The weight of input is expressed as $v_{i}(i=1,2,3 \ldots \ldots m)$ and the weight of output is expressed as $u_{r}(r=1,2,3 \ldots \ldots s)$. The input vector and output vector of the DMUs are expressed as $X_{j}=\left(x_{1 j}, x_{2 j}, x_{3 j} \ldots \ldots x_{m j}\right)^{T}$ and $Y_{j}=\left(y_{1 j}, y_{2 j}, y_{3 j \ldots \ldots} y_{s j}{ }^{T} \cdot \theta\right.$ denotes the efficiency value of DMU, $\varepsilon$ denotes the non-Archimedean, which is less than any positive number but greater than zero. In general, it's $10^{-6} . S^{-}$and $S^{+}$represent the slack variables of inputs and outputs respectively. $\lambda_{j}$ represents the weight coefficient of inputs and outputs.

When the efficiency of decision-making units is evaluated, the traditional DEA model postulates that the greater the output, the higher the efficiency will be. However, when the CEECI is calculated, it contains not only the expected output, but also the non-expected output such as carbon dioxide emissions. So, it is not appropriate to directly use the traditional DEA model. Therefore, it is necessary to transform undesired output into expected output. Refer to the method of linear data transfer function proposed by (Zhu 2002) to convert the variable of carbon emissions into the expected output. The specific method is as follows:

$$
E_{i j}{ }^{*}=-E_{i j}+\max \left(E_{i}\right)+1
$$

where, $E_{i j}{ }^{*}$ represents the carbon emissions of the desired output after the adjustment; $E_{i j}$ indicates the carbon emissions of undesired output; $\max \left(E_{i}\right)$ indicates the largest annual carbon emissions. 
In the second stage, the slack variables of the inputs are viewed as the explained

variables from the first stage. Meanwhile, the environment variables are viewed as the explanatory variables. Then, the SFA model is constructed as follows to eliminate the non-management factors:

$$
\begin{gathered}
S_{i j}=f\left(Z_{j} ; \beta_{i}\right)+V_{i j}+\mu_{i j} \\
(j=1,2,3 \ldots \ldots n ; i=1,2,3 \ldots \ldots m)
\end{gathered}
$$

$Z_{j}$ is the environmental variables; $\beta_{i}$ is the coefficient of the environment variables; $V_{i j}+\mu_{i j}$ is the mixed error; $V_{i j}$ represents the random interference; $\mu_{i j}$ represents the management inefficiency.

In order to have every DMU in the same environment, it is necessary to eliminate the influence of environmental factors and random interference on the CEECI. The adjusted formula is as follows:

$$
\begin{gathered}
X_{i j}{ }^{A}=X_{i j}+\left[\max \left(f\left(Z_{j} ; \hat{\beta}_{i}\right)\right)-f\left(Z_{j} ; \hat{\beta}_{i}\right)\right]+\left[\max \left(v_{i j}\right)-v_{i j}\right] \\
(j=1,2,3 \ldots \ldots n ; i=1,2,3 \ldots \ldots m)
\end{gathered}
$$

where, $X_{i j}{ }^{A}$ is the input after adjustment, $X_{i j}$ is the input before adjustment, $\left[\max \left(f\left(Z_{j} ; \hat{\beta}_{i}\right)\right)-f\left(Z_{j} ; \hat{\beta}_{i}\right)\right]$ denotes the environmental factors after adjustment. $\left[\max \left(v_{i j}\right)-v_{i j}\right]$ indicates that all DMUs are put at the same environmental level.

\section{The third stage: the adjusted DEA model}

The adjusted input-output variable is used to calculate the efficiency value through the DEA-BCC model. At this time, the efficiency value does not include the environmental factors, random interference and other non-managerial factors. Thus, it is more real and effective.

\subsection{Data description}

\subsubsection{Input and output variables}

(1) Input variables. The three variables of capital, labor and energy are chosen. As for the index of capital input, there are differences in the measurements of capital stock in academic circles, and it is difficult to obtain the depreciation rate of fixed assets in the construction industry in China. Therefore, we choose the depreciation value of fixed assets in the construction industry directly as the index of capital input. As for the factors of labor input, the number of employees in the construction industry 
231 is selected as a measure of the input of labor in the construction industry. With regard

232 to the indicators of energy input, the construction industry consumes from a great 233 variety of energy sources; this paper selects eight kinds of energy consumption 234 including raw coal, coke, gasoline, kerosene, diesel oil, fuel oil, liquefied petroleum 235 gas and natural gas.

236 (2) Desired output. Based on the availability of data, this paper adopts gross construction output to measure the expected output.

238 (3) Undesired output. Carbon emissions are the main undesired output in the construction industry. This paper divided the carbon emissions of the construction industry into direct carbon emissions caused by the use of fossil energy and indirect carbon emissions generated by inducing relevant industries. The indirect emission sources are mainly the production of cement, steel, wood, aluminum and glass. Based on the calculation method provided by IPCC, the calculation method of carbon emissions in the construction industry is established as follows:

$$
E_{i j}=E_{(i j) 1}+E_{(i j) 2}=\sum_{r=1}^{8} E_{r} * N C V_{r} * C E F_{r} * C O F_{r} * \frac{44}{12}+\sum_{r=1}^{5} G_{r} * \varepsilon_{r} *\left(1-\alpha_{r}\right)
$$

$I$ and $J$ represent the year and region; $E_{(i j) 1}$ represents the direct carbon emissions;

$E_{(i j) 2}$ represents the indirect carbon emissions; $r$ represents the type of fossil fuel; $E$

represents the consumption of fossil fuel; NCV 、CEF and COF represent the low calorific value, the carbon content and the rate of carbon oxidation respectively. The product of three variables represents the carbon emission coefficient. These are shown in Table 1. $G$ represents the amount of building materials; $\varepsilon_{r}$ represents the coefficient

251 of carbon emissions per unit of building materials, $\alpha_{r}$ represents the recovery 252 coefficient of building materials. which refers to the research of (Feng et al. 2014).

Table 1 Carbon emission coefficients of various fossil fuels.

\begin{tabular}{lllll}
\hline Fossil fuel & $\begin{array}{l}\text { Low calorific } \\
\text { value }(\mathrm{kJ} / \mathrm{kg})\end{array}$ & $\begin{array}{l}\text { Carbon } \\
\text { content } \\
(\mathrm{kgC} / \mathrm{GJ})\end{array}$ & $\begin{array}{l}\text { the rate of } \\
\text { carbon } \\
\text { oxidation }(-)\end{array}$ & $\begin{array}{l}\text { Carbon emissions } \\
\text { coefficients }(\mathrm{tC} / \mathrm{t})\end{array}$ \\
\hline raw coal & 20908 & 25.8 & 0.913 & 0.4925 \\
coke & 28435 & 29.2 & 0.928 & 0.7705 \\
gasoline & 43070 & 18.9 & 0.98 & 0.7977 \\
kerosene & 43070 & 19.5 & 0.986 & 0.8281
\end{tabular}




\begin{tabular}{lllll} 
diesel oil & 42652 & 20.2 & 0.982 & 0.8461 \\
fuel oil & 41816 & 21.1 & 0.985 & 0.8691 \\
liquefied petroleum gas & 50179 & 17.2 & 1.000 & 0.8631 \\
natural gas & $38931\left(\mathrm{~kJ} / \mathrm{m}^{3}\right)$ & 15.3 & 0.990 & $0.5896\left(\mathrm{tC} / \mathrm{m}^{3}\right)$ \\
\hline
\end{tabular}

Data source: The low calorific value of energy from the General Principles of Comprehensive Energy Consumption Calculation (GB/T 2589-2008), and the default carbon content and carbon oxidation factor of energy combustion from the IPCC National Greenhouse Gas Inventory Guidelines in 2006.

\subsubsection{The external environmental variables affected by non-management}

The external environment should satisfy the hypothesis of separation. It means that they have an impact on the CEECI, but are not subject to the subjective control of the development of that industry (Simar and Wilson 2007). As to the features of CEECI, this paper chose environmental variables affecting the CEECI from five aspects; these include the GDP, the level of industrialization, the degree of opening to the outside world, technological innovation and energy structure. At the same time, the indicators are measured respectively by the ratio of the GNP, the added value of the tertiary industry to GDP, the total import and export volume, the number of patent applications and the ratio of the electricity consumption to the total energy consumption.

\subsubsection{Sample selection and data sources}

This paper analyzes the dynamic evolution of CEECI through selecting 30 provinces of China from 2006 to 2017 mainly. Due to the availability of data, the

271 Tibet was not included in the scope of the analysis. The data is mainly from the China

272 Construction Industry Statistical Yearbook (2007-2018), the China Energy Statistical 273 Yearbook (2007-2018) and the China Statistical Yearbook (2007-2018). The 274 descriptive statistics of each variable are shown in Table 2: Table 2 Descriptive statistics of each variable.

\begin{tabular}{lllll}
\hline Variables & Mean & Std. Dev. & Min & Max \\
\hline Capital (Unit: 100 million Yuan) & 189.9 & 159.3 & 2.031 & 899.0 \\
Labor (Unit: Ten thousand) & 157.6 & 157.0 & 2.137 & 894.9 \\
Energy (Unit: Ten thousand tons of standard coal) & 110.1 & 71.89 & 7.924 & 348.1 \\
Desired output (Unit: 100 million Yuan) & 4182 & 4668 & 64.94 & 27957 \\
Undesired output (Unit: Ten thousand tons) & 8745 & 15447 & 96.90 & 130991 \\
The GDP (Unit: 100 million Yuan) & 17783 & 15642 & 648.5 & 89705 \\
The level of industrialization & 42.55 & 9.160 & 28.60 & 80.56 \\
The degree of opening-up & 1090 & 1910 & 5.87 & 10900 \\
(Unit: 100 million Dollar) & 57789 & 93355 & 325 & 627834 \\
Technological innovation (Unit: one piece) & 0.142 & 0.0373 & 0.0724 & 0.245 \\
Energy structure & & & &
\end{tabular}


277 4.1 The comprehensive CEECI of the traditional DEA model in the first stage

278 Table 3 lists shows that the input-oriented DEA-BCC model can analyze the 279 comprehensive CEECI from 2006 to 2017. Firstly, there are three areas including 280 Jiangsu, Zhejiang and Hainan, where the values of the comprehensive CEECI are 1.

281 However, there is varying degrees of room for improvement in other regions. This is 282 basically consistent with the research conclusions of ( $\mathrm{Lu}$ et al. 2015). Secondly, the 283 comprehensive CEECI is constantly increasing, which is increased from 0.792 in 2842006 to 0.844 in 2017. Thirdly, during the period from 2006 to 2017, the 285 comprehensive CEECI in six provinces was lower than 0.7, including Xinjiang,

286 Shanxi, Shandong, Yunnan, Gansu and Inner Mongolia. Taking Inner Mongolia as an 287 example, it can be seen that the comprehensive average CEECI in Inner Mongolia is 288 only 0.564 , far below than the national average.

289

Table 3 The comprehensive CEECI from 2006 to 2017.

\begin{tabular}{|c|c|c|c|c|c|c|c|c|c|c|c|c|c|c|}
\hline Region & Provinces & 2006 & 2007 & 2008 & 2009 & 2010 & 2011 & 2012 & 2013 & 2014 & 2015 & 2016 & 2017 & Average \\
\hline \multirow[t]{5}{*}{ North China } & Beijing & 0.928 & 0.963 & 0.958 & 0.997 & 0.995 & 1 & 1 & 1 & 1 & 1 & 1 & 1 & 0.987 \\
\hline & Tianjin & 1 & 1 & 1 & 1 & 1 & 0.702 & 0.767 & 0.584 & 0.808 & 0.960 & 0.942 & 0.822 & 0.882 \\
\hline & Hebei & 0.711 & 0.709 & 0.703 & 0.821 & 0.896 & 0.786 & 0.786 & 0.830 & 0.853 & 0.792 & 0.784 & 0.674 & 0.779 \\
\hline & Shanxi & 0.742 & 0.748 & 0.713 & 0.825 & 0.786 & 0.585 & 0.567 & 0.588 & 0.622 & 0.612 & 0.606 & 0.627 & 0.668 \\
\hline & Inner Mongolia & 0.574 & 0.573 & 0.573 & 0.621 & 0.646 & 0.461 & 0.460 & 0.479 & 0.582 & 0.583 & 0.608 & 0.610 & 0.564 \\
\hline \multirow{3}{*}{$\begin{array}{l}\text { Northeast } \\
\text { China }\end{array}$} & Liaoning & 0.680 & 0.680 & 0.668 & 0.692 & 0.718 & 0.651 & 0.771 & 0.830 & 0.801 & 0.706 & 0.692 & 0.735 & 0.719 \\
\hline & Jilin & 0.716 & 0.708 & 0.661 & 0.745 & 0.723 & 0.692 & 0.716 & 0.722 & 0.775 & 0.650 & 0.672 & 0.702 & 0.707 \\
\hline & Heilongjiang & 1 & 1 & 1 & 1 & 1 & 1 & 0.975 & 0.737 & 0.825 & 0.938 & 0.915 & 1 & 0.949 \\
\hline \multirow[t]{7}{*}{ East China } & Shanghai & 1 & 1 & 1 & 1 & 1 & 0.799 & 0.661 & 0.682 & 0.821 & 0.869 & 0.912 & 0.954 & 0.892 \\
\hline & Jiangsu & 1 & 1 & 1 & 1 & 1 & 1 & 1 & 1 & 1 & 1 & 1 & 1 & 1 \\
\hline & Zhejiang & 1 & 1 & 1 & 1 & 1 & 1 & 1 & 1 & 1 & 1 & 1 & 1 & 1 \\
\hline & Anhui & 0.669 & 0.711 & 0.690 & 0.759 & 0.783 & 0.799 & 0.784 & 0.778 & 0.858 & 0.905 & 0.878 & 0.874 & 0.791 \\
\hline & Fujian & 0.929 & 1 & 0.697 & 0.729 & 0.798 & 0.794 & 0.829 & 0.863 & 0.853 & 0.909 & 0.920 & 0.918 & 0.853 \\
\hline & Jiangxi & 1 & 1 & 0.925 & 0.973 & 1 & 1 & 1 & 0.981 & 1 & 1 & 1 & 0.964 & 0.987 \\
\hline & Shandong & 0.576 & 0.606 & 0.601 & 0.634 & 0.645 & 0.628 & 0.599 & 0.622 & 0.678 & 0.701 & 0.690 & 0.679 & 0.638 \\
\hline \multirow[t]{3}{*}{ Central China } & Henan & 0.880 & 0.868 & 0.968 & 0.866 & 0.837 & 0.820 & 0.742 & 0.696 & 0.774 & 0.723 & 0.742 & 0.775 & 0.808 \\
\hline & Hubei & 0.718 & 0.726 & 0.721 & 0.770 & 0.813 & 1 & 0.665 & 0.769 & 0.971 & 0.946 & 0.99 & 0.985 & 0.840 \\
\hline & Hunan & 0.678 & 0.723 & 0.670 & 0.739 & 0.799 & 0.724 & 0.707 & 0.722 & 0.784 & 0.826 & 0.865 & 0.828 & 0.755 \\
\hline \multirow[t]{3}{*}{ South China } & Guangdong & 0.814 & 0.800 & 0.774 & 0.794 & 0.843 & 0.754 & 0.721 & 0.736 & 0.823 & 0.881 & 0.862 & 0.881 & 0.807 \\
\hline & Guangxi & 0.762 & 0.784 & 0.876 & 0.956 & 1 & 1 & 1 & 1 & 1 & 1 & 1 & 1 & 0.948 \\
\hline & Hainan & 1 & 1 & 1 & 1 & 1 & 1 & 1 & 1 & 1 & 1 & 1 & 1 & 1 \\
\hline \multirow{4}{*}{$\begin{array}{l}\text { Southwest } \\
\text { China }\end{array}$} & Chongqing & 0.654 & 0.701 & 0.636 & 0.778 & 0.794 & 0.795 & 0.858 & 0.881 & 0.944 & 0.968 & 0.961 & 0.902 & 0.823 \\
\hline & Sichuan & 0.557 & 0.577 & 0.579 & 0.671 & 0.660 & 0.597 & 0.748 & 0.778 & 0.789 & 0.875 & 0.887 & 0.819 & 0.711 \\
\hline & Guizhou & 0.723 & 0.712 & 0.661 & 0.773 & 0.789 & 0.672 & 0.734 & 0.858 & 0.902 & 0.991 & 0.941 & 1 & 0.813 \\
\hline & Yunnan & 0.583 & 0.581 & 0.562 & 0.665 & 0.695 & 0.513 & 0.557 & 0.613 & 0.643 & 0.670 & 0.679 & 0.709 & 0.623 \\
\hline \multirow{5}{*}{$\begin{array}{l}\text { Northwest } \\
\text { China }\end{array}$} & Shaanxi & 0.836 & 0.933 & 0.761 & 0.860 & 0.943 & 0.776 & 0.716 & 0.684 & 0.762 & 0.823 & 0.812 & 0.816 & 0.810 \\
\hline & Gansu & 0.464 & 0.535 & 0.482 & 0.540 & 0.605 & 0.528 & 0.608 & 0.707 & 0.728 & 0.755 & 0.743 & 0.649 & 0.612 \\
\hline & Qinghai & 0.965 & 1 & 0.883 & 0.958 & 1 & 0.831 & 0.868 & 0.870 & 0.984 & 0.873 & 0.826 & 0.833 & 0.908 \\
\hline & Ningxia & 0.952 & 0.866 & 0.618 & 0.661 & 0.640 & 0.552 & 0.562 & 0.607 & 0.670 & 0.708 & 0.822 & 0.866 & 0.710 \\
\hline & Xinjiang & 0.648 & 0.629 & 0.657 & 0.718 & 0.702 & 0.673 & 0.627 & 0.672 & 0.753 & 0.737 & 0.714 & 0.697 & 0.686 \\
\hline Average & & 0.792 & 0.804 & 0.768 & 0.818 & 0.837 & 0.771 & 0.768 & 0.776 & 0.833 & 0.847 & 0.849 & 0.844 & 0.809 \\
\hline
\end{tabular}


to further eliminate both the influence of different environmental factors and random interference and make further analysis on the CEECI.

\subsection{The SFA Regression Analysis at the Second Stage}

In the second stage, the slacks of the three inputs of construction industry were taken as the explained variables; these were calculated by the traditional DEA model in the first stage. At the same time, five environmental variables were selected as the explanatory variables. The SFA model was constructed to eliminate the influence of external environmental factors and random interference on input relaxation variables. The original inputs were adjusted. According to the estimated SFA results in Table 4, the $\gamma$ of the three SFA models all passed the significance test at the $1 \%$ level, indicating that the selection of environmental variables is reasonable. At the same time, the one-tail error of LR passed the significance test of $1 \%$ in the three SFA models, which demonstrates that it is appropriate and necessary to eliminate the influence of environmental variables with non-management factors when the CEECI is investigated.

When the impact of environmental factors on inputs is analyzed, the positive coefficient of environmental factors indicates that increasing the value of environmental factors will lead to an increase in input slacks. This situation means that when the degree of utilization of the construction industry inputs is reduced, it will not be conducive to improvements in CEECI.

It can be seen from Table 4 that when the level of economic development is improved, the input slacks of energy consumption in the construction industry and the fixed asset depreciation will be significantly increased. This indicates that improvements in the level of economic development will increase the degree of relaxation of energy consumption and capital input. It means that the effective utilization of inputs will be reduced, which is not conducive to improvements in the CEECI.

The level of industrialization has a significant negative effect on the slacks of energy consumption and capital, but has a significant positive effect on the slack of 
labor. This indicates that with improvements to industrialization levels, the slacks of energy consumption and capital in the construction industry decrease, which is conducive to the improvements of CEECI. However, when the level of industrialization is improved, the slacks of labor input will increase and resources will not be fully utilized, which is not conducive to the improvement of the CEECI.

There is a significant negative correlation between the input slacks of technical level and labor, which indicates that with the improvements in technical level, the input slack of labor will decrease and the degree of resource utilization will increase. At the same time, the increase of technical level is conducive to increasing the total output value of the construction industry, reducing the emission of air pollutants and improving the production efficiency of the construction industry. Therefore, it has a positive impact that improving the regional technical level for the CEECI.

The degree of opening to the outside world has a significant negative correlation with the input slack of energy consumption in the construction industry. However, the input slacks of labor and capital fail to pass the correlation test. This indicates that, as the degree of the opening to the outside world is increased, there is a decrease in the slack of energy consumption in the construction industry, which is conducive to improvements in CEECI.

There is a significant negative correlation between the input slacks of energy consumption structure and energy consumption and capital in construction industry. It indicates that, with the optimization of the energy consumption structure, the input slacks of energy consumption and capital in the construction industry gradually decrease, which is beneficial to the improvement of CEECI. As the improvement of energy structure is conducive to reducing the emission of air pollutants. In addition, the capital investment for controlling the emission of pollutants will be correspondingly reduced. Therefore, it will have a beneficial impact on improving the CEECI.

From the above analysis, it can be seen that environmental factors have different influences on input relaxation, which makes the construction industry in different 


\section{Environmental factors
Economic development
the lever of industrialization}

Technological innovation

The degree of opening-up

Energy structure

Constant

Sigma-squared

gamma

Log likelihood function

One-tail error of LR
Table 4 The SFA estimation results of CEECI.

\begin{tabular}{ccc} 
Energy consumption & Labor & Capital \\
\hline $15.2031^{* * *}$ & 2.1731 & $10.2365^{* *}$ \\
$(5.1173)$ & $(0.8784)$ & $(2.3900)$ \\
$-10.0561^{* * *}$ & $2.6477^{*}$ & $-18.0442^{* * *}$ \\
$(-3.8133)$ & $(1.7664)$ & $(-4.8997)$ \\
3.0239 & $-3.3787^{* *}$ & 2.0995 \\
$(1.2150)$ & $(-2.4482)$ & $(0.8954)$ \\
$-10.5004^{* * *}$ & -2.3560 & -0.5879 \\
$(-3.6395)$ & $(-0.8605)$ & $(-0.1378)$ \\
$-2.1217^{*}$ & 0.0187 & $-2.6893^{* *}$ \\
$(-1.7540)$ & $(0.0286)$ & $(-2.2085)$ \\
$-1.6433^{*}$ & -0.560 & 0.0922 \\
$(-1.8679)$ & $(-1.2810)$ & $(0.1502)$ \\
$22.6976^{* * *}$ & $11.9027^{* * *}$ & $26.8505^{* * *}$ \\
$(4.4332)$ & $(3.6715)$ & $(2.4868)$ \\
$0.7057^{* * *}$ & $0.8378^{* * *}$ & $0.7898^{* * *}$ \\
-0.8869 & -0.6735 & -0.8623 \\
$149.6025^{* * *}$ & $195.4936^{* * *}$ & $94.2129^{* * *}$ \\
\hline
\end{tabular}

Notes: $* * *, * *, *$ denote the level of significance at $1 \%, 5 \%$, and $10 \%$, t-value is in parentheses.

\subsection{The Empirical Results of the DEA Model with the Adjusted Inputs at the} Third Stage

Table 5 lists the real CEECI in 30 provinces of China after excluding the influence of environment factors and random interference. Firstly, the real CEECI in Jiangsu, Zhejiang and Hainan is higher than that of other provinces. And their efficiency value is 1 . However, the real CEECI in Sichuan Province is far lower than that of other provinces, which is 0.752 . This shows that although the interference of external environmental factors has been eliminated, there are still regional differences in CEECI. It is due to uneven regional development. Secondly, the real CEECI in provinces with a higher level of economic development in China, which is higher than that in economically underdeveloped areas. There are obvious regional differences between them. For example, the real CEECI in Jiangsu and Zhejiang in East China is much higher than that in Sichuan Province in Southwest China. Thirdly, the average real CEECI is 0.936. And except for Sichuan Province, the efficiency values are all 
Table 5 The real CEECI from 2006 to 2017.

\begin{tabular}{|c|c|c|c|c|c|c|c|c|c|c|c|c|c|c|}
\hline Region & Provinces & 2006 & 2007 & 2008 & 2009 & 2010 & 2011 & 2012 & 2013 & 2014 & 2015 & 2016 & 2017 & Average \\
\hline \multirow[t]{5}{*}{ North China } & Beijing & 0.884 & 0.956 & 0.896 & 0.945 & 0.976 & 1 & 1 & 1 & 1 & 1 & 1 & 0.998 & 0.971 \\
\hline & Tianjin & 1 & 1 & 1 & 1 & 1 & 0.904 & 0.907 & 0.819 & 0.909 & 0.981 & 0.995 & 0.935 & 0.954 \\
\hline & Hebei & 0.915 & 0.961 & 0.942 & 0.973 & 0.970 & 0.815 & 0.851 & 0.852 & 0.965 & 0.802 & 0.781 & 0.929 & 0.896 \\
\hline & Shanxi & 0.950 & 0.952 & 0.933 & 0.961 & 0.943 & 0.876 & 0.874 & 0.827 & 0.792 & 0.566 & 0.819 & 0.893 & 0.866 \\
\hline & Inner Mongolia & 0.948 & 0.946 & 0.829 & 0.878 & 0.885 & 0.922 & 0.922 & 0.885 & 0.939 & 0.922 & 0.932 & 0.916 & 0.910 \\
\hline \multirow[t]{3}{*}{ Northeast China } & Liaoning & 0.905 & 0.900 & 0.900 & 0.879 & 0.871 & 0.870 & 0.898 & 0.928 & 0.881 & 0.917 & 0.935 & 0.974 & 0.905 \\
\hline & Jilin & 0.967 & 0.955 & 0.953 & 0.971 & 0.965 & 0.927 & 0.549 & 0.920 & 0.917 & 0.918 & 0.869 & 0.881 & 0.899 \\
\hline & Heilongjiang & 1 & 1 & 1 & 1 & 1 & 1 & 1 & 0.982 & 0.993 & 0.999 & 1 & 1 & 0.998 \\
\hline \multirow[t]{7}{*}{ East China } & Shanghai & 1 & 1 & 1 & 1 & 1 & 0.921 & 0.839 & 0.830 & 0.941 & 0.923 & 1 & 1 & 0.955 \\
\hline & Jiangsu & 1 & 1 & 1 & 1 & 1 & 1 & 1 & 1 & 1 & 1 & 1 & 1 & 1 \\
\hline & Zhejiang & 1 & 1 & 1 & 1 & 1 & 1 & 1 & 1 & 1 & 1 & 1 & 1 & 1 \\
\hline & Anhui & 0.934 & 0.935 & 0.924 & 0.950 & 0.938 & 0.903 & 0.943 & 0.939 & 0.963 & 0.985 & 0.970 & 0.959 & 0.945 \\
\hline & Fujian & 0.991 & 1 & 0.954 & 0.950 & 0.963 & 0.950 & 0.966 & 0.796 & 0.819 & 0.858 & 0.809 & 0.772 & 0.902 \\
\hline & Jiangxi & 0.999 & 1 & 1 & 1 & 1 & 1 & 1 & 0.998 & 1.000 & 0.987 & 1 & 0.988 & 0.998 \\
\hline & Shandong & 0.902 & 0.846 & 0.848 & 0.854 & 0.845 & 0.868 & 0.828 & 0.898 & 0.841 & 0.854 & 0.899 & 0.896 & 0.865 \\
\hline \multirow[t]{3}{*}{ Central China } & Henan & 1 & 1 & 1 & 0.947 & 0.926 & 0.951 & 0.871 & 0.735 & 0.827 & 0.788 & 0.897 & 0.905 & 0.904 \\
\hline & Hubei & 0.889 & 0.889 & 0.886 & 0.900 & 0.920 & 1 & 0.847 & 0.909 & 1 & 1 & 1 & 1 & 0.937 \\
\hline & Hunan & 0.904 & 0.916 & 0.811 & 0.923 & 0.943 & 0.937 & 0.948 & 0.918 & 0.929 & 0.953 & 0.980 & 0.950 & 0.926 \\
\hline \multirow[t]{3}{*}{ South China } & Guangdong & 0.984 & 0.960 & 0.966 & 0.970 & 0.980 & 0.954 & 0.860 & 0.876 & 0.893 & 0.940 & 0.983 & 0.943 & 0.942 \\
\hline & Guangxi & 0.996 & 0.996 & 1 & 1 & 1 & 1 & 1 & 1 & 1 & 1 & 1 & 1 & 0.999 \\
\hline & Hainan & 1 & 1 & 1 & 1 & 1 & 1 & 1 & 1 & 1 & 1 & 1 & 1 & 1 \\
\hline \multirow{4}{*}{$\begin{array}{l}\text { Southwest } \\
\text { China }\end{array}$} & Chongqing & 0.907 & 0.933 & 0.914 & 0.927 & 0.930 & 0.961 & 0.974 & 0.947 & 0.963 & 0.980 & 0.973 & 0.945 & 0.946 \\
\hline & Sichuan & 0.598 & 0.607 & 0.603 & 0.679 & 0.672 & 0.611 & 0.781 & 0.829 & 0.834 & 0.968 & 0.976 & 0.863 & 0.752 \\
\hline & Guizhou & 0.980 & 0.980 & 0.975 & 0.980 & 0.984 & 0.970 & 0.984 & 0.994 & 0.980 & 0.996 & 0.852 & 1 & 0.973 \\
\hline & Yunnan & 0.920 & 0.923 & 0.901 & 0.926 & 0.928 & 0.851 & 0.876 & 0.872 & 0.853 & 0.894 & 0.893 & 0.885 & 0.894 \\
\hline \multirow[t]{5}{*}{$\begin{array}{l}\text { Northwest } \\
\text { China }\end{array}$} & Shaanxi & 0.981 & 0.999 & 0.929 & 0.952 & 0.981 & 0.953 & 0.920 & 0.903 & 0.919 & 0.949 & 0.989 & 0.985 & 0.955 \\
\hline & Gansu & 0.937 & 0.933 & 0.916 & 0.929 & 0.924 & 0.923 & 0.928 & 0.955 & 0.942 & 0.955 & 0.950 & 0.937 & 0.936 \\
\hline & Qinghai & 0.997 & 0.995 & 0.964 & 0.964 & 0.993 & 0.972 & 0.973 & 0.928 & 0.948 & 0.887 & 0.876 & 0.879 & 0.948 \\
\hline & Ningxia & 0.989 & 0.990 & 0.965 & 0.957 & 0.961 & 0.960 & 0.961 & 0.957 & 0.919 & 0.873 & 0.982 & 0.984 & 0.958 \\
\hline & Xinjiang & 0.957 & 0.966 & 0.966 & 0.969 & 0.959 & 0.942 & 0.932 & 0.909 & 0.945 & 0.943 & 0.939 & 0.930 & 0.946 \\
\hline Average & & 0.948 & 0.951 & 0.933 & 0.946 & 0.949 & 0.931 & 0.914 & 0.914 & 0.930 & 0.928 & 0.943 & 0.945 & 0.936 \\
\hline
\end{tabular}

370

The Gaussian Kernel is used to estimate the time evolution of CEECI, as shown

371 in Fig. 2. First, from the position of variable distribution, the CEECI takes 2010 and

3722013 as the boundary, showing a trend of first moving to the left and then moving to

373 the right. This situation demonstrates that the overall level of CEECI decreased and

374 then increased, showing a fluctuating upward trend. There is no obvious change in the

375 right skewed distribution pattern of each efficiency, which indicates that the CEECI is

376 still mostly in high efficiency areas. Secondly, the number of peaks consists of one

377 main peak and one side peak, which gradually evolves into one main peak, showing

378 that the CEECI gap is gradually decreasing. Thirdly, the number of peaks was one

379 side peak to the left of a main peak, and evolved into a main peak gradually. It shows

380 that the phenomenon of multi-polarization of CEECI is reduced. 


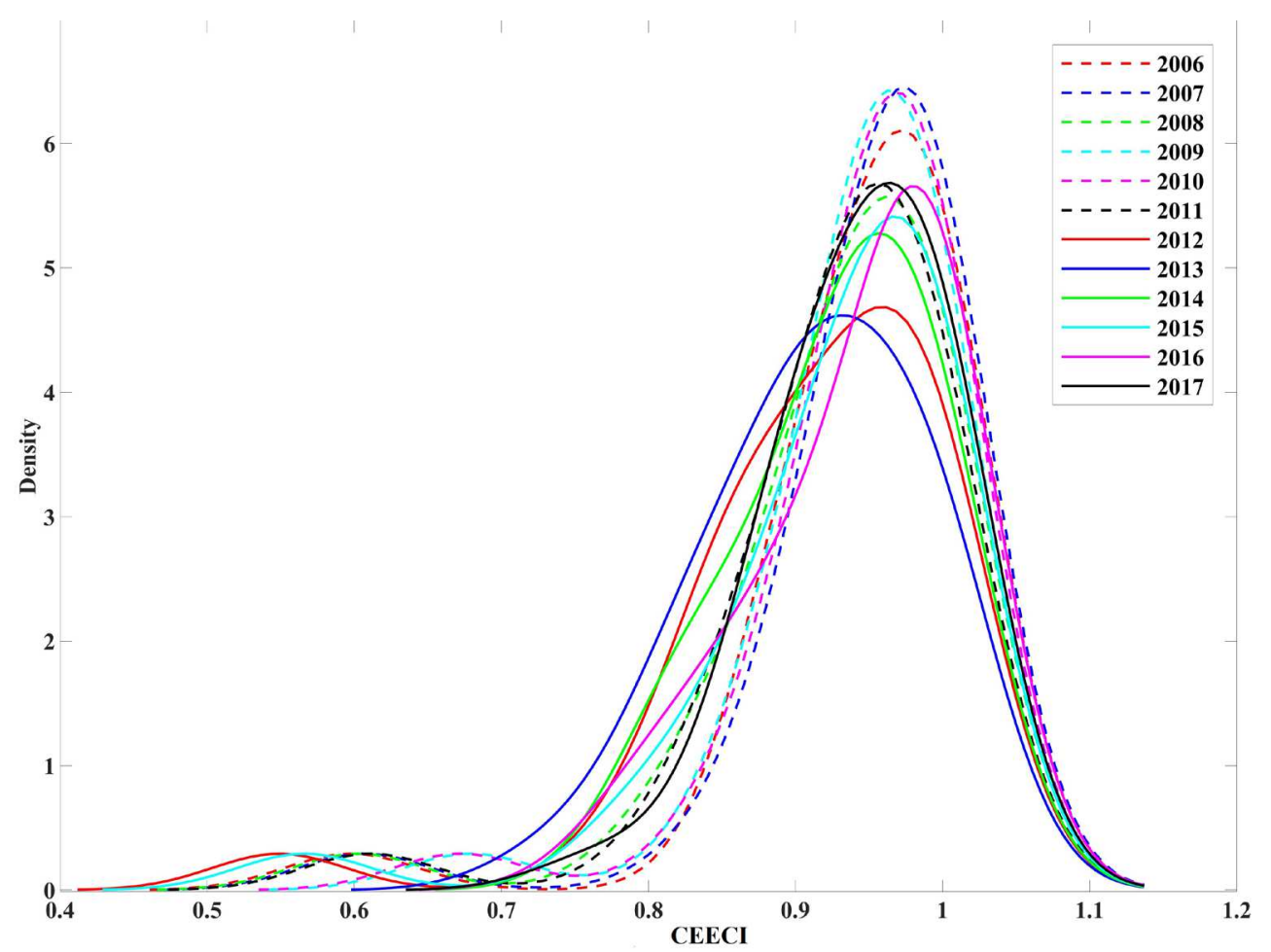

Fig. 2 Gaussian kernel density distribution of the real CEECI

\section{Comparative discussion and policy implications}

\subsection{Comparison of comprehensive and real CEECI}

A comparison of Table 3 and 5 indicates three points. Firstly, compared with the first stage, the CEECI has obviously improved from 0.809 to 0.936 , which has increased by $16 \%$. It shows that the external environment of China's construction industry has significant potential for improvement. Secondly, the average CEECI in North China, Northeast China, East China, Central China, South China, Southwest China and Northwest China increased by $18.49 \%, 18 \%, 8.18 \%, 15.15 \%, 6.78 \%$, $21.75 \%$ and $27.1 \%$ respectively from 2006 to 2017 . This shows that environmental factors and random interference underestimate the CEECI. At the same time, it is confirmed again that an analysis of the SFA model is necessary and meaningful in the second stage.

Fig. 3 compares the comprehensive and real CEECI in 30 provinces. According to Fig. 3c, it can be found that after removing the influence of environment factors and random interference, the rankings of 10 provinces have risen significantly. Among them, Ningxia, Xinjiang, Gansu, Inner Mongolia, Guizhou and Shaanxi have 
increased their rankings by more than five. Most of these areas are located in northwest and southwest China. Because these provinces have relatively weak economic development, technological innovation and energy structure and other external environment, their CEECI is relatively low. Take Inner Mongolia as an example, according to the China Construction Industry Statistical Yearbook, the average annual energy consumption of the construction industry in Inner Mongolia was 161.71 ten thousand tons of standard coal between 2006 and 2017, which is much higher than the national average of 106.43 ten thousand tons of standard coal in the construction industry. There is a large energy input in the construction industry of these areas. And the long-term coal-led energy structure has hindered the construction industry from transforming into a green, energy-saving intelligent building industry. At the same time, the economic development in Northwest and Southwest China is relatively backward. It is less attractive to high-quality talents in the construction industry, which leads to the low quality and weak technology of the front-line operators in the construction industry. Therefore, it is difficult for the to improve CEECI from environmental factors such as economic development, energy structure and technological innovation and so on.

On the contrary, after excluding the environmental factors, the CEECI in Fujian Province dropped by 13 ranks. It is the province with the largest decline. This shows that Fujian has created an external environment conducive to the green development of the construction industry. This shows that Fujian has created an external environment, which is conducive to the green development of the construction industry. Fujian Province has successively promulgated a number of policies and regulations such as the Green Building Development Regulations in Fujian Province. And the Fujian Province continues to optimize the industrial structure and takes smart construction as a new direction for the development of the construction industry. During the "13th Five-Year" plan (2016-2020) period, Fujian Province has completed a total output value of 5.6 trillion yuan in construction industry, an average annual growth rate of $12 \%$, which is among the highest in the country. As a result, the CEECI 
in Fujian decreased from 11 in the first stage to 24 in the third stage. It is indicated that the external environment has a significant effect on improving the CEECI in Fujian.

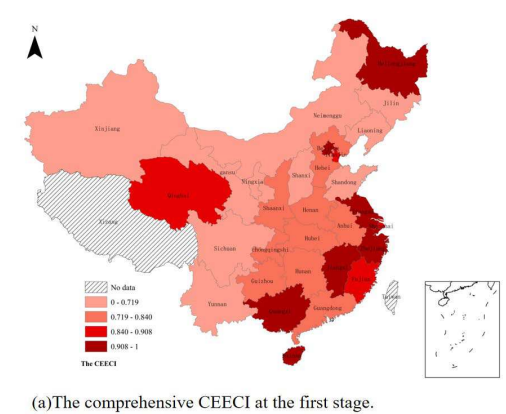

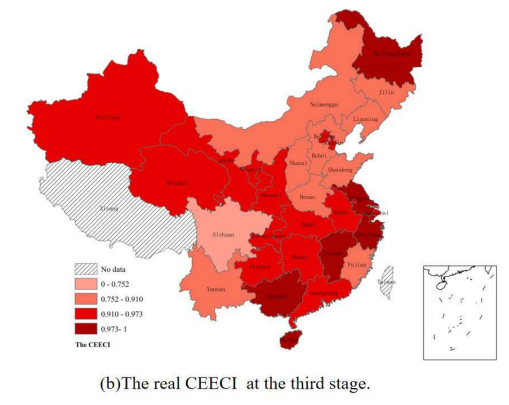

(b)The real CEECI at the third stage.

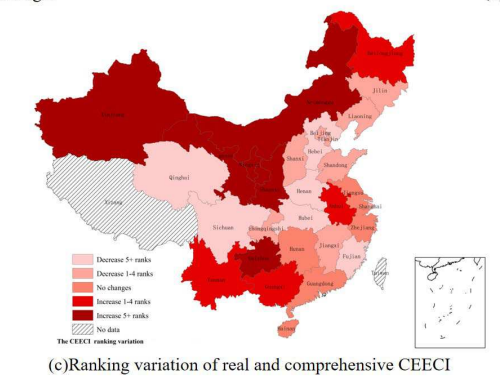

Fig. 3. Comparison of the comprehensive and real CEECI from 2006 to 2017.

\subsection{Decomposition of the real CEECI}

In order to further analyze the reasons for the change of the actual CEECI, it is decomposed into pure technical efficiency and scale efficiency. The PCEE removes the impact of economies of scale and reflects how to use production technology to maximize the expected output of the construction industry, and it reduces the emission of air pollutants. The scale efficiency (SE) indicates the effective degree of economies of scale.

Fig. 4 shows the real CEECI, PCEE and SE trends of the construction industry in 30 provinces and seven regions of China. It can be found that the change trend of SE is most similar to the real CEECI. This shows that the CEECI is mainly determined by SE. Taking Northeast China as an example, SE in Northeast China dropped to the lowest value in 2012. Although PCEE increased slightly, the real CEECI was closest to SE, and the lowest value during the study period occurred in 2012. Similarly, the SE in the Southwest is similar to the real CEECI, showing obvious fluctuation and rising trend. Compared with PCEE, SE in China's seven major regions is relatively small, which is in the increasing returns to scale stage. It is necessary to accelerate the 
development of green and energy-saving intelligent construction industry, reduce the emission of building pollutants, improve the efficiency of carbon emission in construction industry and develop economies of scale. After 2013, PCEE showed an obvious upward trend. Among them, the PCEE in South China remained at 1 from 2011 to 2017. It is worth noting that in May 2011, the Chinese government promulgated the Outline of Construction Industry Informatization Development from 2011 to 2015, which may continue to promote the transformation of China's construction industry to informatization and intelligence. This has had a powerful impact on PCEE in the construction industry. efficiency
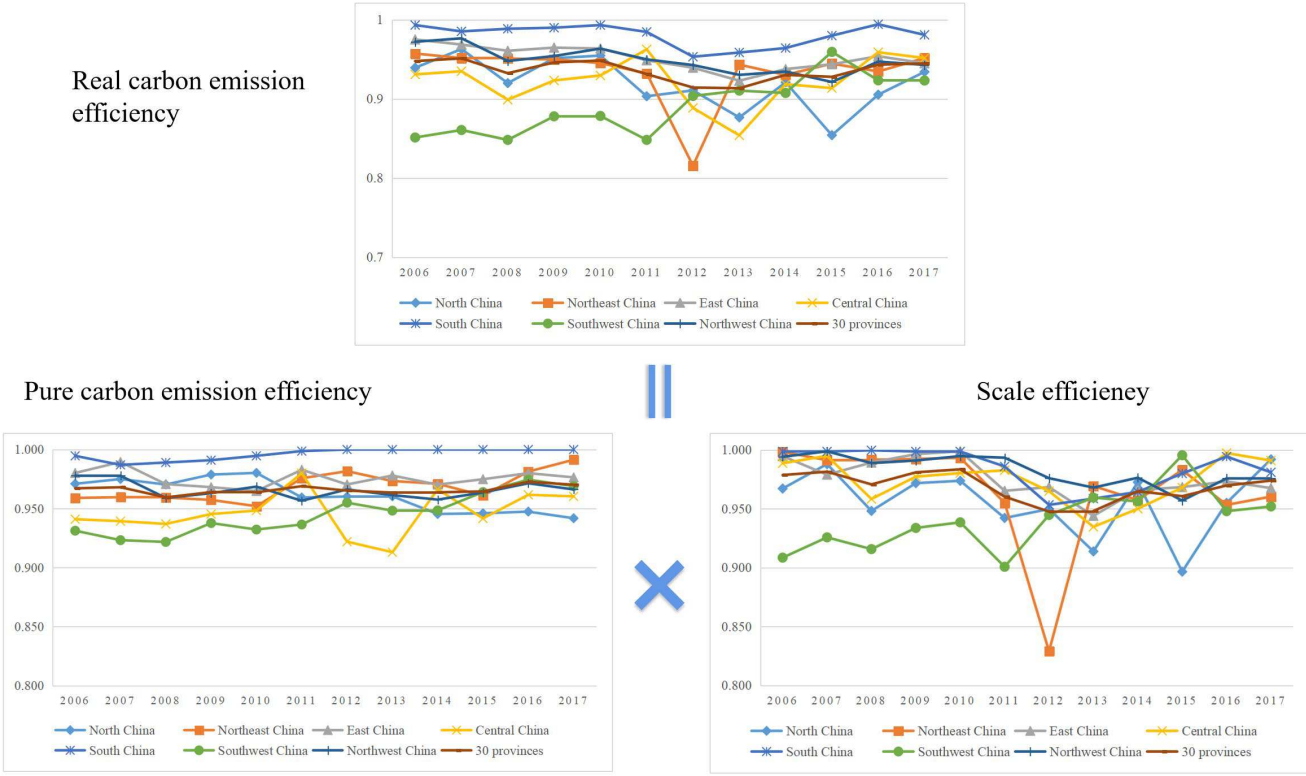

Fig. 4. Decomposition of the real CEECI from 2006 to 2017.

In order to further study the inter-provincial differences in CEECI, the average PTE of 0.966 and the average SE of 0.968 were taken as the critical points of efficiency. Meanwhile, the PTE was classified into four categories: "High-High", "Low-High", "High-Low" and "Low-Low", as shown in Fig. 5.

The first category is the type of "High-High". It mainly includes 11 regions in Beijing, Zhejiang, Jiangsu, Hainan, Jiangxi, Heilongjiang, Chongqing, Shaanxi, Guangxi, Ningxia, and Guizhou. The PCEE and SE of the construction industry in these areas is relatively high, reaching more than 0.96 . It indicates that the scale of resource allocation for construction industry carbon emissions is reasonable in these 
regions, and the level of management and decision-making for inputs is high, which makes the comprehensive CEECI higher. However, the PCEE of Chongqing and Shaanxi is relatively low, which is located at the bottom of area "High-High". Compared with Jiangsu and Hainan, there is still room for improvement.

The second category is "Low-High". The PCEE is high, but the SE is lower than the national average of 7 provinces, including Shanghai, Tianjin, Guangdong, Hebei, Fujian, Jilin and Qinghai. These provinces should focus on improving the scale economy of construction industry. Especially in Hebei, Jilin and Fujian provinces, the SE is far lower than the national average level of 0.968. In addition, the SE in Tianjin is 0.966 , which needs to be increased by $2.1 \%$ to enter the "high and high" region. Therefore, it is necessary to focus on improving the SE of the construction industry, raising the level of resource allocation and making it achieve economies of scale. Only in this way, can these provinces improve the green development level of the construction industry.

The third category is the "High-Low", which including Shandong, Liaoning, Anhui, Hunan, Hubei, Xinjiang, Yunnan and Gansu. The value of SE is high in these areas, and there is a big gap between the value of PCEE and the national average. The value of PCEE in Shandong province is 0.892, which is the lowest in China. Therefore, these provinces need to intensify innovation. At the same time, the lever of information technology in the construction industry should be improved to develop green and energy-saving intelligent buildings. Furthermore, provinces in these regions need to further improve the level of management relating to the inputs and decisionmaking effectiveness of the construction industry. These measures can improve the CEECI.

The fourth category is the type of "Low-Low", which mainly includes Henan, Shanxi, Sichuan and Inner Mongolia. The overall level of CEECI in these parts is low, and both PCEE and SE have some space for improvement in varying degrees. This may be caused by the characteristics of resource endowment. According to the data of China Energy Statistics Yearbook, the energy consumption input of construction 
industry in Henan, Shanxi, Sichuan an d Inner Mongolia is 127.23,108.89,154.18 and 161.71 ten thousand tons of standard coal respectively. This data is much higher than the national average of 106.43 ten thousand tons of standard coal. It is necessary to optimize the energy structure of construction industry and increase the use of clean energy, which is consistent with the research conclusion of (Zhang et al. 2017). In addition, these provinces are located in the Central, Southwest and North China, which have a low level of economic development and technology. They contribute less to the CEECI. Therefore, both SE and PCEE need to be further improved, which can promote the improvement of CEECI.

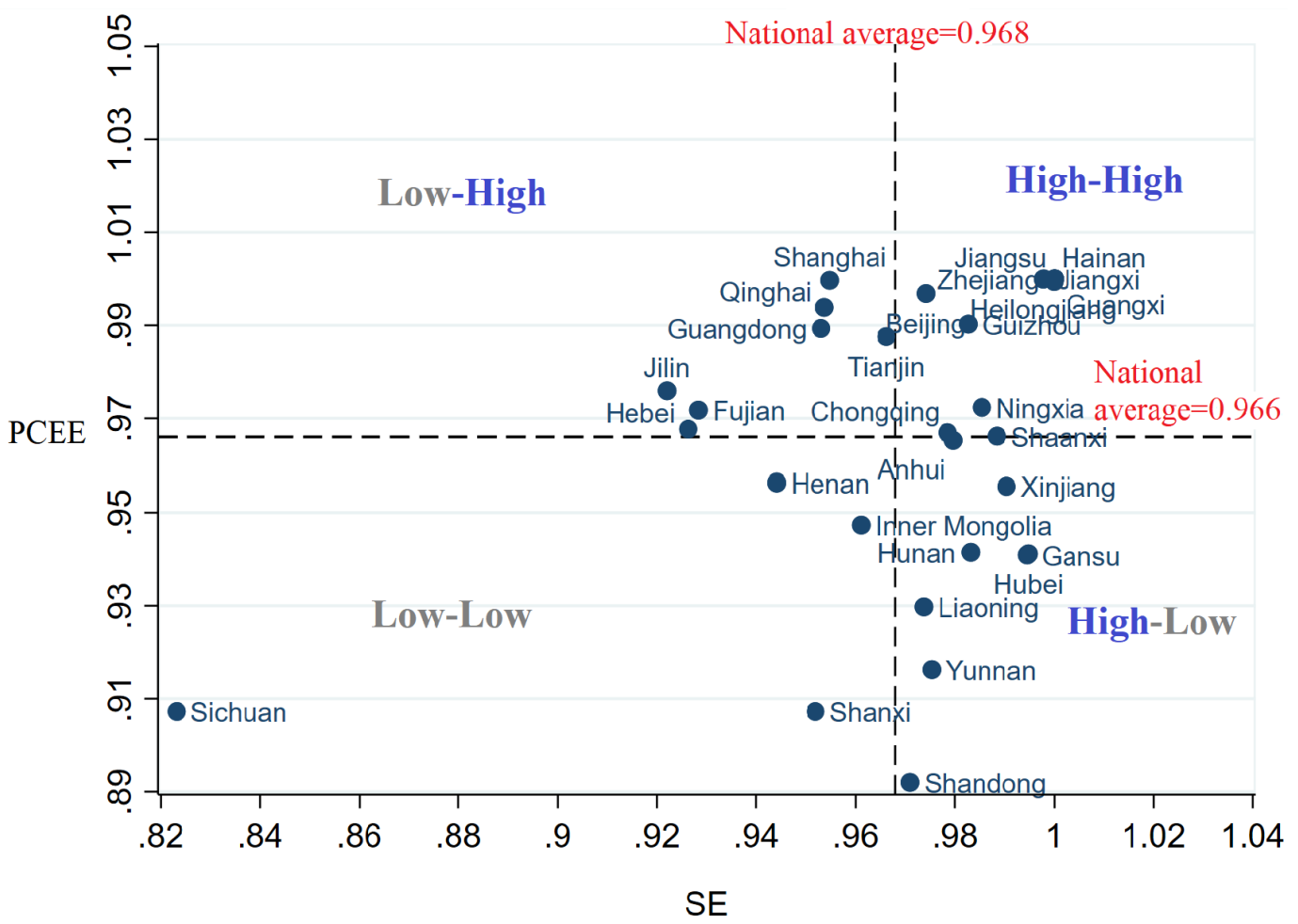

Fig. 5 The Decomposition of real CEECI in different regions

\subsection{Analysis of the internal influencing factors of the CEECI.}

In order to further analyze the internal factors affecting the CEECI, this paper excludes the influence of external environmental factors and random interference, taking the real CEECI, PCEE and SE of the third stage as dependent variables, and selecting the level of development (Ind), the energy structure (Energy), the amount of labor (Labor), the total power of construction machinery and equipment $(\mathrm{P})$ and the construction intensity of construction industry (Cci) as influencing factors. Taking the 
added value of construction industry, the ratio of coal consumption to total energy consumption in the construction industry, the number of laborers in the construction industry at the end of the year, the total power of self-owned construction machinery and equipment at the end of the year and the ratio of construction area to added value in construction industry as specific indicators, the stochastic Tobit model is constructed as follows:

$$
\begin{gathered}
\text { CEECI }_{i t}=\beta_{0}+\beta_{1} \text { lnInd }_{i t}+\beta_{2} \text { Energy }_{i t}+\beta_{3} \text { lnLabor }_{i t}+\beta_{4} \ln P_{i t}+\beta_{5} \text { Cci }_{i t}+\varepsilon_{i t} \\
\text { PCEE }_{i t}=\beta_{0}+\beta_{1} \text { lnInd }_{i t}+\beta_{2} \text { Energy }_{i t}+\beta_{3} \text { LnLabor }_{i t}+\beta_{4} \ln P_{i t}+\beta_{5} \text { Cci }_{i t}+\varepsilon_{i t} \\
S E_{i t}=\beta_{0}+\beta_{1} \text { lnInd }_{i t}+\beta_{2} \text { Energy }_{i t}+\beta_{3} \text { lnLabor }_{i t}+\beta_{4} \ln P_{i t}+\beta_{5} \text { Cci }_{i t}+\varepsilon_{i t}
\end{gathered}
$$

Where, $i$ and $t$ represent the index value of enterprise $i$ in the first year; $\beta_{0}$ is the constant, $\beta_{1-5}$ is the coefficient that is estimated for each influencing factor and $\varepsilon_{i t}$ is the random interference. See Table 6 for the estimated results.

By observing Table 6, it can be found that the development level of the construction industry has a significant positive effect on the CEECI, PCEE and SE of its carbon emissions. It indicates that the higher the development level of the construction industry, the higher its CEECI will be. One possible reason is that the higher the development level of the construction industry, the higher the technical level of carbon emissions. The reason is that increasing the development level of the construction industry will improve the technical level of carbon emissions to a certain extent, which is conducive to the economic development in an efficient and lowcarbon way. However, the energy structure, the number of workers, the total power of construction machinery and equipment and the construction intensity of construction industry can inhibit the CEECI, PCEE and SE of carbon emissions in construction industry. A possible reason is that when the construction industry needs more and more labor, its labor-intensive characteristics are more obvious. The degree of science and technology is correspondingly lower, which may inhibit the improvement of CEECI. When the total power of construction machinery and construction intensity in the construction industry is greater, the demand for energy is greater. This situation 
means that the more greenhouse gases, such as carbon dioxide, are produced, the lower the CEECI will be when the technical level of carbon emissions is limited.

Table 6 Estimated results of internal influencing factors of CEECI.

\begin{tabular}{llll}
\hline Variable & CEECI & PCEE & SE \\
\hline Ind & $6.53 \mathrm{e}-09^{* * *}$ & $3.40 \mathrm{e}-09^{* * *}$ & $4.49 \mathrm{e}-09^{* * *}$ \\
& $(4.32)$ & $(4.05)$ & $(3.45)$ \\
Energy & -0.0006 & -0.0003 & -0.0006 \\
& $(-0.75)$ & $(-0.76)$ & $(-0.76)$ \\
Labor & $-0.0258^{*}$ & $-0.0171^{* *}$ & -0.0201 \\
& $(-1.91)$ & $(-2.50)$ & $(-1.47)$ \\
$P$ & $-0.0515^{* * *}$ & $-0.0183^{* *}$ & $-0.0321^{* *}$ \\
& $(-3.48)$ & $(-2.29)$ & $(-2.32)$ \\
Cci & $-0.0001^{* *}$ & $-0.0001^{* *}$ & $-0.0001^{* *}$ \\
& $(-2.03)$ & $(-1.99)$ & $(-2.03)$ \\
Constant & $1.3970^{* * *}$ & $1.1732^{* * *}$ & $1.2892^{* * *}$ \\
& $(16.62)$ & $(24.42)$ & $(17.81)$ \\
Control time & YES & YES & NO \\
control individual & YES & YES & NO \\
N & 360 & 360 & 360 \\
\hline
\end{tabular}

\subsection{Enlightenment}

(1) Firstly, government decision-makers should refer to the real CEECI after excluding the external environment and random interference items, so as to make more effective policies and regulations. Due to the different external environments such as the economic development, technological innovation and energy structure of various provinces in China, the traditional DEA model cannot eliminate the differences in the external environment of the construction industry. As a result, the CEECI in each province does not match the actual situation. Therefore, government departments should base their decisions on the actual CEECI. At the same time, taking into account the differences in the external environment of various provinces, the government scientifically formulates relevant policies to improve the CEECI and promote the green development of the construction industry.

(2) The external environment must be ameliorated to improve the CEECI. First, enterprises should both optimize the energy consumption structure of the construction industry and increase the technological development of the construction industry, so as to both improve the production technology of building materials and the transformation mechanism of low-carbon science and technology. In addition, green 
561 building materials and clean energy sources such as nuclear power and wind energy

562 will be developed. By developing high technology, the energy consumption structure 563 can be optimized and upgraded and the CEECI improved. Second, the provinces 564 should exchange and learn more about the concept of low-carbon and efficient production and management in the construction industry. The Central and Western regions of China should take the initiative to learn the carbon emission technology and advanced management systems and concepts of the construction industry in the Eastern region. It can reduce the differences and imbalances in regional development. Third, we should strengthen the degree of opening to the outside world and introduce foreign advanced carbon emission technologies. It can promote the spillover effect of

571 knowledge and technology and improve the overall level of CEECI, so as to better cope with international emission reduction targets.

(3) The differences in CEECI should be considered fully and relevant policies in a targeted manner formulated. Firstly, the PTE and SE are the type of "Low-Low" areas represented by Henan, Shanxi and Sichuan. These areas should strengthen innovation in management concepts and reform management systems. At the same time, the scale benefits of the construction industry should be noted, so as to promote the development from disorder to standardization and from dispersion to intensive.

579 Secondly, the type of the "Low-High" areas represented by Shanghai, Tianjin, Guangdong and so on, have lower CEECI caused by lower SE. For the areas, attention should be paid to large-scale development, but the more urgent task in the type of "High-Low" is to strengthen innovation of management systems and methods which can promote the efficient development of carbon emissions in the construction industry. Thirdly, Beijing, Zhejiang, Jiangsu and other "High-High" areas are ideal in terms of PTE and SE. However, it is still necessary to continue to strengthen the management innovation of carbon emissions input resources in the construction industry on the existing basis. At the same time, there should be a strengthening of the industrialization and intensive development of the construction industry in order to improve economies of scale. 


\section{Conclusion}

The traditional DEA model ignores the influence of environmental variables and random interference terms, which may lead to deviations in CEECI. Therefore, this paper adopts a three-stage DEA model to eliminate those environmental variables and random interference affected by non-management factors. It more accurately measures the CEECI in 30 regions of China from 2006 to 2017. The influencing factors of CEECI are analyzed using the Tobit model and the conclusions are summarized as follows:

(1) The CEECI will indeed be affected by external environmental variables. After excluding environmental variables and random interference, the average CEECI increased by $16 \%$. This verifies the existence of environmental factors and random interference. The CEECI was underestimated the traditional DEA model.

(2) There are regional differences in CEECI. The CEECI in South China, East China and Northwest China is higher than North China, Northeast China, Central China and Southwest China. However, with the development of time, both the multipolarization phenomenon of CEECI is reduced and the regional development gap is reduced. From a single province, after excluding the environmental factors and random interference, the rankings of Ningxia, Xinjiang, Gansu and Inner Mongolia have increased by more than five. The external environment of these provinces is not conducive to the improvement of CEECI. On the contrary, the rankings of CEECI in Fujian, Qinghai and Sichuan have obviously declined.

(3) The real CEECI is decomposed into PCEE and SE. It is found that the CEECI is mainly determined by SE. At the same time, according to the national average level of PCEE and SE, China's 30 provinces are divided into four categories, and each group has specific methods to improve the CEECI.

(4) Considering the influence of external environmental variables on input slacks, the estimation results show that the level of economic development, the technological innovation, the degree of opening-up and energy structure have a significant positive impact on the CEECI. In addition, with improvements in industrialization, the slack of 
energy and capital in the construction industry decreases. This promotes improvements in CEECI, although it may lead to increasing slack in labor investment, which, in turn, has an inhibitory effect on the CEECI.

(5) According to the internal influencing factors of CEECI, the energy structure, the number of workers, the total power of construction machinery and the construction intensity of the construction industry can inhibit the CEECI, PCEE and SE of carbon emissions in the construction industry with the development level of the construction industry having a significant positive effect on it.

Ethics approval and consent to participate: We confirmed that this man-uscript has not been published elsewhere and is not under consideration by another journal. Ethical approval and informed consent do not apply to this study.

Consent for publication: Not applicable Availability of data and materials: The datasets used and/or analyzed during the current study are available from the corresponding author on reasonable request.

Competing interests: The authors declare no conflict of interest.

Authors' contributions: Conceptualization: M.Z. and Z.C.; data curation: M.Z.; formal analysis: M.Z. and L.L.; methodology: L.L. and Z.C.; project administration: L.L. and Z.C.; software: M.Z.; supervision: Z.C. and L.L.; Validation: M.Z. and L.L.; writing — original draft: M.Z.; writing—review and editing: M.Z., L.L. and Z.C. All authors read and approved the final manuscript.

Funding: No funding was received to assist with the preparation of this manuscript. Acknowledgements: We are thankful for the suggestions from Liang $\mathrm{Li}$ at Nanjing University of Information Science \&Technology on an earlier version of the paper. We are thankful for the suggestions and efforts from the reviewers and editors.

\section{References}

Banker R D, Charnes A, Cooper W (1984) Some models for estimating technical and scale inefficiencies in data envelopment analysis. Manage Sci 30 (9): 1078-1092.

Cai B, Guo H, Ma Z, Wang Z, Dhakal S, Cao L (2019) Benchmarking carbon emissions efficiency in Chinese cities: A comparative study based on high-resolution gridded data. Appl Energy 242: 9941009 .

Cheng Z, Li L, Liu J, Zhang H (2018) Total-factor carbon emission efficiency of China's provincial industrial sector and its dynamic evolution. Renewable and Sustainable Energy Reviews 94: 330-339.

Cui Q, Li Y (2014) The evaluation of transportation energy efficiency: An application of three-stage virtual frontier DEA. Transport Res Part D-Transport Environ 29: 1-11.

Dong F, Li X, Long R, Liu X (2013) Regional carbon emission performance in China according to a stochastic frontier model. Renewable and Sustainable Energy Reviews 28: 525-530.

Feng C, Wang M (2017) The economy-wide energy efficiency in China's regional building industry. 
Energy 141: 1869-1879.

Feng M, Li X (2020) Evaluating the efficiency of industrial environmental regulation in China: A three-stage data envelopment analysis approach. J Clean Prod 242: 118535.

Ferreira A, Pinheiro M D, Brito J, Mateus R (2018) Combined carbon and energy intensity benchmarks for sustainable retail stores. Energy 165: 877-889.

Fried H O, Lovell C K, Schmidt S S, Yaisawarng S (2002) Accounting for environmental effects and statistical noise in data envelopment analysis. J Prod Anal 17 (1-2): 157-174.

Feng B, Wang X, Liu B (2014) Provincial Variation in Energy Efficiency Across China's Construction Industry with Carbon Emission Considered. Resources Science 36(06):1256-1266.

Hu J, Wang S (2006) Total-factor energy efficiency of regions in China. Energy Policy 34 (17): 32063217.

Huo T, Tang M, Cai W, Ren H, Liu B, Hu X (2020) Provincial total-factor energy efficiency considering floor space under construction: an empirical analysis of China's construction industry. $\mathrm{J}$ Clean Prod 244: 118749.

Jaraite J, Maria C D (2012) Efficiency, productivity and environmental policy: A case study of power generation in the EU. Energy Econ 34 (5): 1557-1568.

Jin T, Kim J (2019) A comparative study of energy and carbon efficiency for emerging countries using panel stochastic frontier analysis. Sci Rep 9 (1): 1-8.

Li J, Ma J, Wei W (2020) Analysis and Evaluation of the Regional Characteristics of Carbon Emission Efficiency for China. Sustainability 12 (8): 3138.

Li K, Lin B (2015) How does administrative pricing affect energy consumption and CO2 emissions in China? Renewable and Sustainable Energy Reviews 42: 952-962.

Li K, Lin B (2016) Impact of energy conservation policies on the green productivity in China's manufacturing sector: Evidence from a three-stage DEA model. Appl Energy 168: 351-363.

Lin B, Liu H (2015) CO2 mitigation potential in China's building construction industry: A comparison of energy performance. Build Environ. 94: 239-251.

Li H, He H, Shan J, Cai J (2020) Research on technology innovation efficiency of China's IC industry eliminating the influence of non-operating factors: Analysis based on generalized GRA-DEA and Tobit. Journal of Industrial Engineering 34(02):60-70.

Chen Y, Liu B, Shen Y, Wang X (2016) The energy efficiency of China's regional construction industry based on the three-stage DEA model and the DEA-DA model. KSCE J Civ Eng 20(1)

Liu H, Zhang Z, Zhang T, Wang L (2020) Revisiting China's provincial energy efficiency and its influencing factors. Energy 208: 118361.

Lu J, Zhang R, Hu K (2015) Anlysis of Low Carbon Behavior Efficiency in China's Construction Industry. Engineering Journal of Wuhan University 48 (06): 809-813.

Long R, Shao T, Chen H (2016) Spatial econometric analysis of China's province-level industrial carbon productivity and its influencing factors. Appl Energy 166: 210-219.

Pretis F, Roser M (2017) Carbon dioxide emission-intensity in climate projections: Comparing the observational record to socio-economic scenarios. Energy 135: 718-725.

Simar L, Wilson P W (2007) Estimation and inference in two-stage, semi-parametric models of production processes. J Econom 136 (1): 31-64.

Sun W, Huang C (2020) How does urbanization affect carbon emission efficiency? Evidence from China. J Clean Prod 272: 122828.

Tan B, Yavuz Y, Otay E N, Çamlıbel E (2016) Optimal selection of energy efficiency measures for 
energy sustainability of existing buildings. Comput Oper Res 66: 258-271.

Vujović T, Petković Z, Pavlović M, Jović S (2018) Economic growth based in carbon dioxide emission intensity. Physica A 506: 179-185.

Wu W, Ren C, Wang Y, Liu T, Li L (2018) DEA-Based Performance Evaluation System for Construction Enterprises Based on BIM Technology. J Comput Civil Eng 32 (2): 04017081.

Xu B, Lin B (2016) Assessing CO2 emissions in China's iron and steel industry: A dynamic vector autoregression model. Appl Energy 161: 375-386. Xue X, Wu H, Zhang X, Dai J, Su C (2015) Measuring energy consumption efficiency of the construction industry: the case of China. J Clean Prod 107: 509-515.

711 Yamaji K, Matsuhashi R, Nagata Y, Kaya Y (1993) A study on economic measures for CO2 reduction in Japan. Energy Policy 21 (2): 123-132.

713 Yan D, Lei Y, Li L, Song W (2017) Carbon emission efficiency and spatial clustering analyses in 714 China's thermal power industry: Evidence from the provincial level. J Clean Prod 156: 518-527. Yan J, Zhao T, Lin T, Li Y (2017) Investigating multi-regional cross-industrial linkage based on sustainability assessment and sensitivity analysis: a case of construction industry in China. J Clean Prod 142: 2911-2924.

718 Zhang J, Liu Y, Chang Y, Zhang L (2017) Industrial eco-efficiency in China: A provincial quantification using three-stage data envelopment analysis. J Clean Prod 143: 238-249. Zhao H, Guo S, Zhao H (2019) Provincial energy efficiency of China quantified by three-stage data envelopment analysis. Energy 166: 96-107. Zhou Y, Kong Y, Zhang T (2020) The spatial and temporal evolution of provincial eco-efficiency in China based on SBM modified three-stage data envelopment analysis. Environ Sci Pollut Res 27 (8): 8557-8569. 142(1): 16-20. 


\section{Figures}

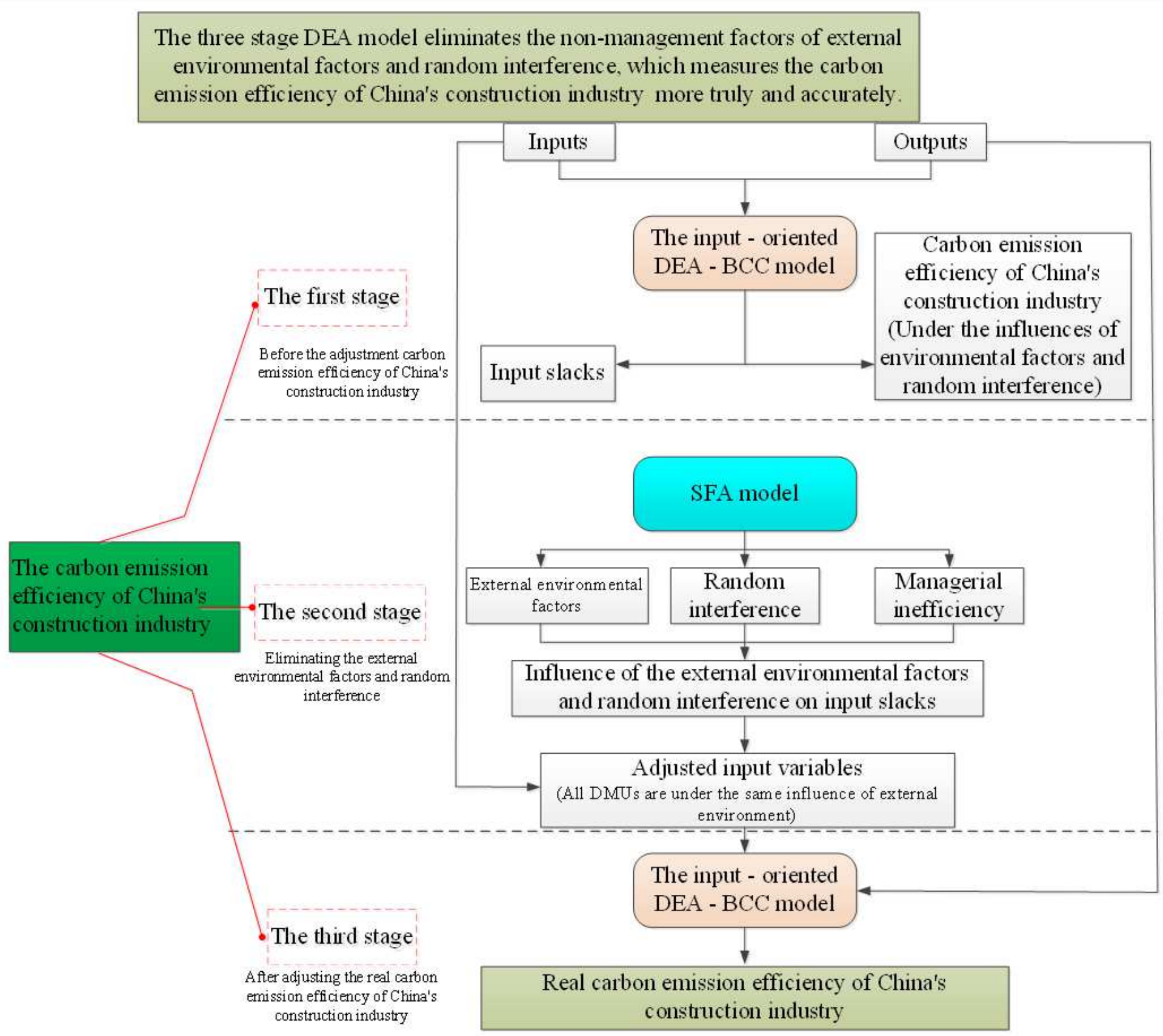

Figure 1

Three-stage DEA model. 


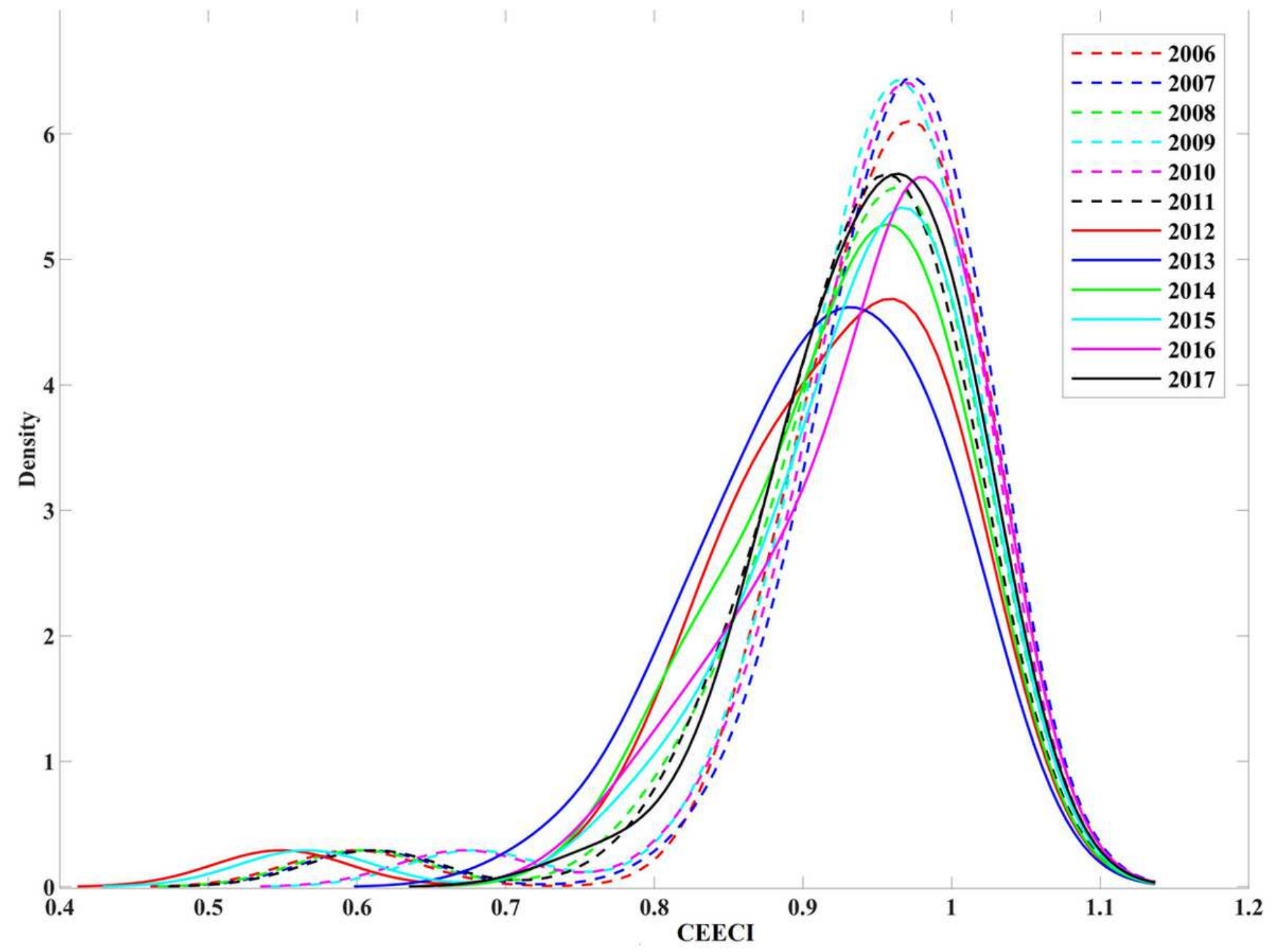

Figure 2

Gaussian kernel density distribution of the real CEECI 


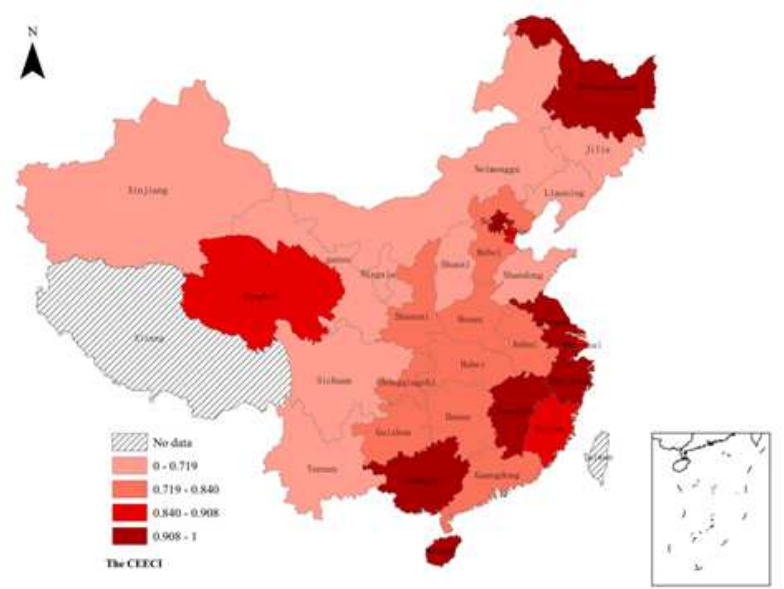

(a)The comprehensive CEECI at the first stage.

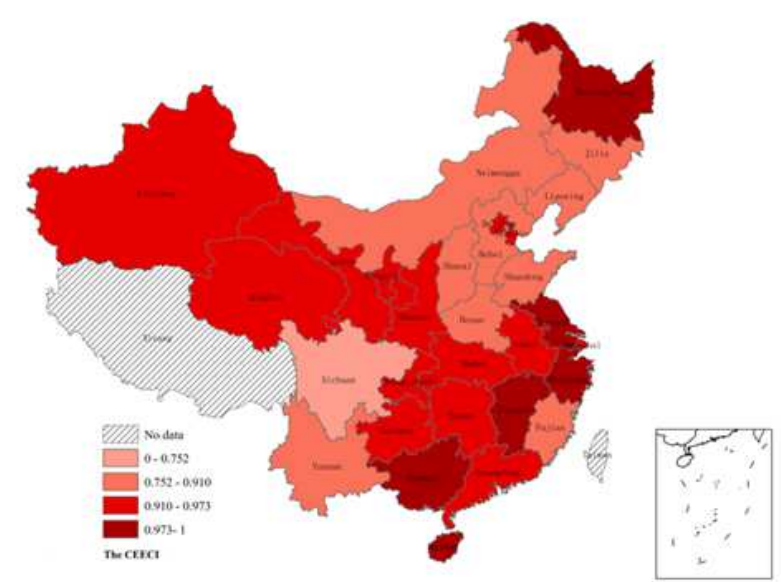

(b) The real CEECI at the third stage.

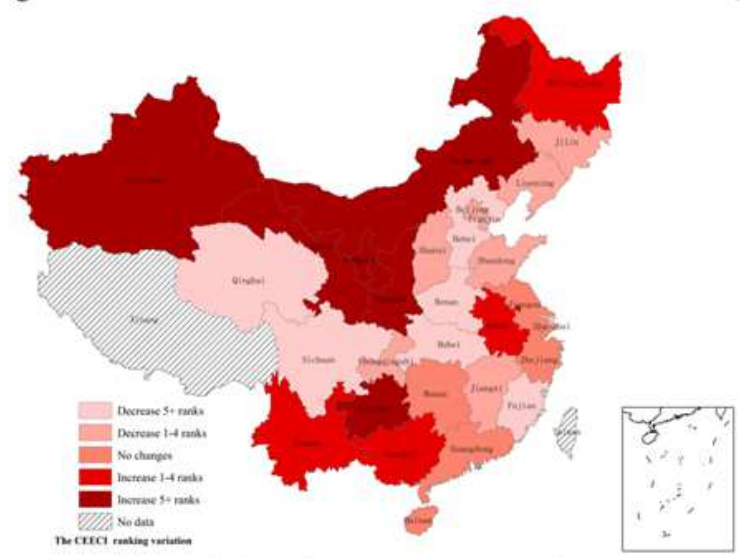

(c)Ranking variation of real and comprehensive CEECI

\section{Figure 3}

Comparison of the comprehensive and real CEECI from 2006 to 2017. Note: The designations employed and the presentation of the material on this map do not imply the expression of any opinion whatsoever on the part of Research Square concerning the legal status of any country, territory, city or area or of its authorities, or concerning the delimitation of its frontiers or boundaries. This map has been provided by the authors. 
Real carbon emission efficiency

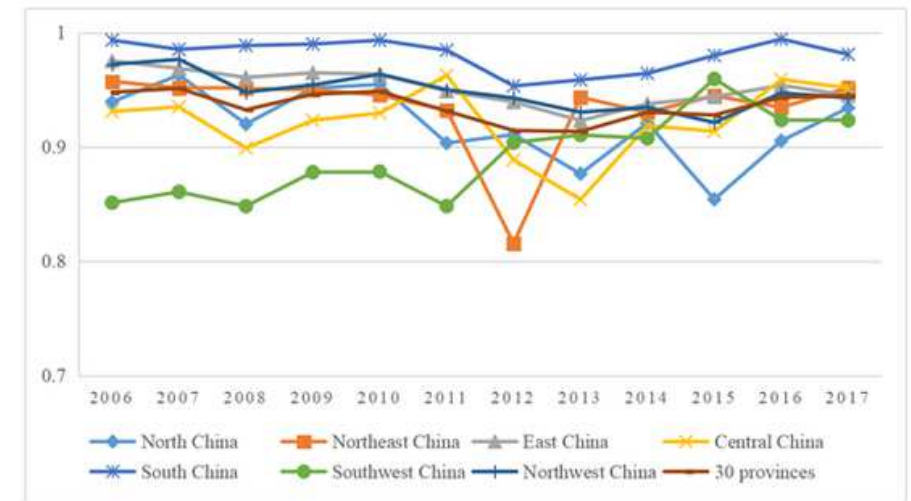

Pure carbon emission efficiency

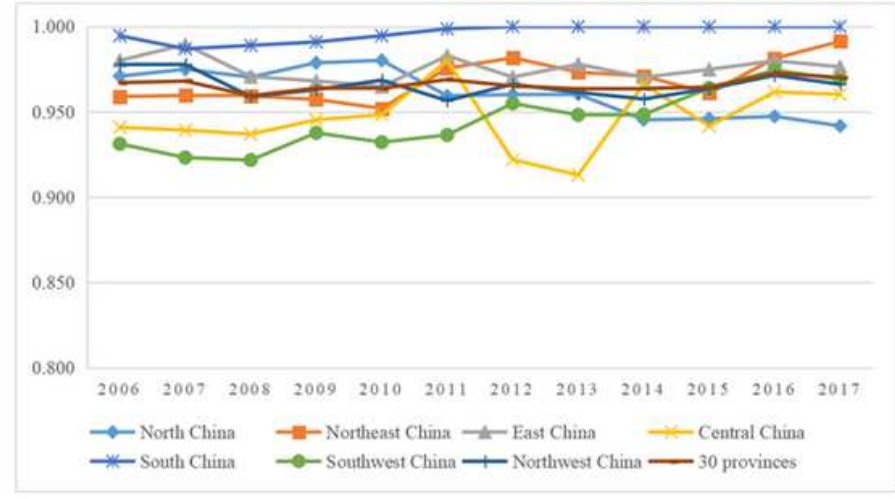

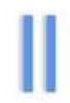

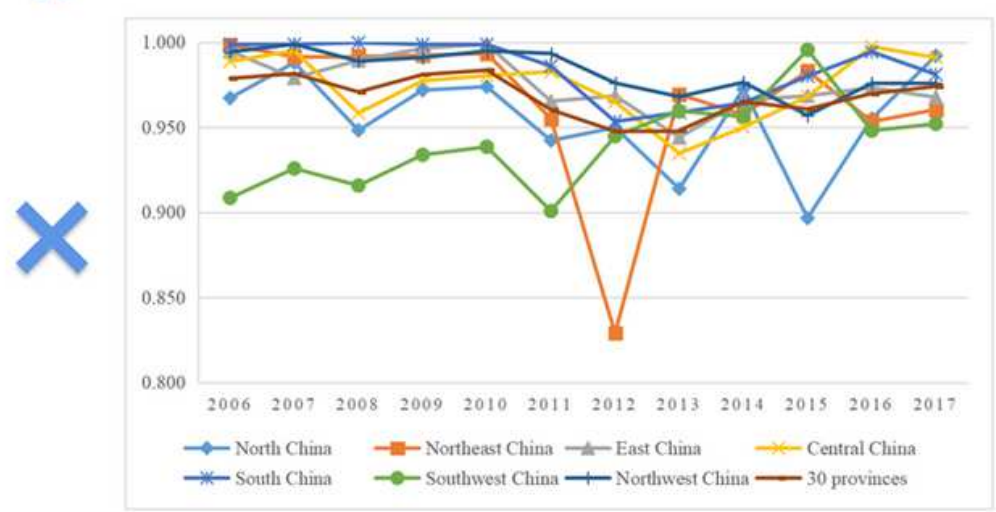

\section{Figure 4}

Decomposition of the real CEECI from 2006 to 2017. 


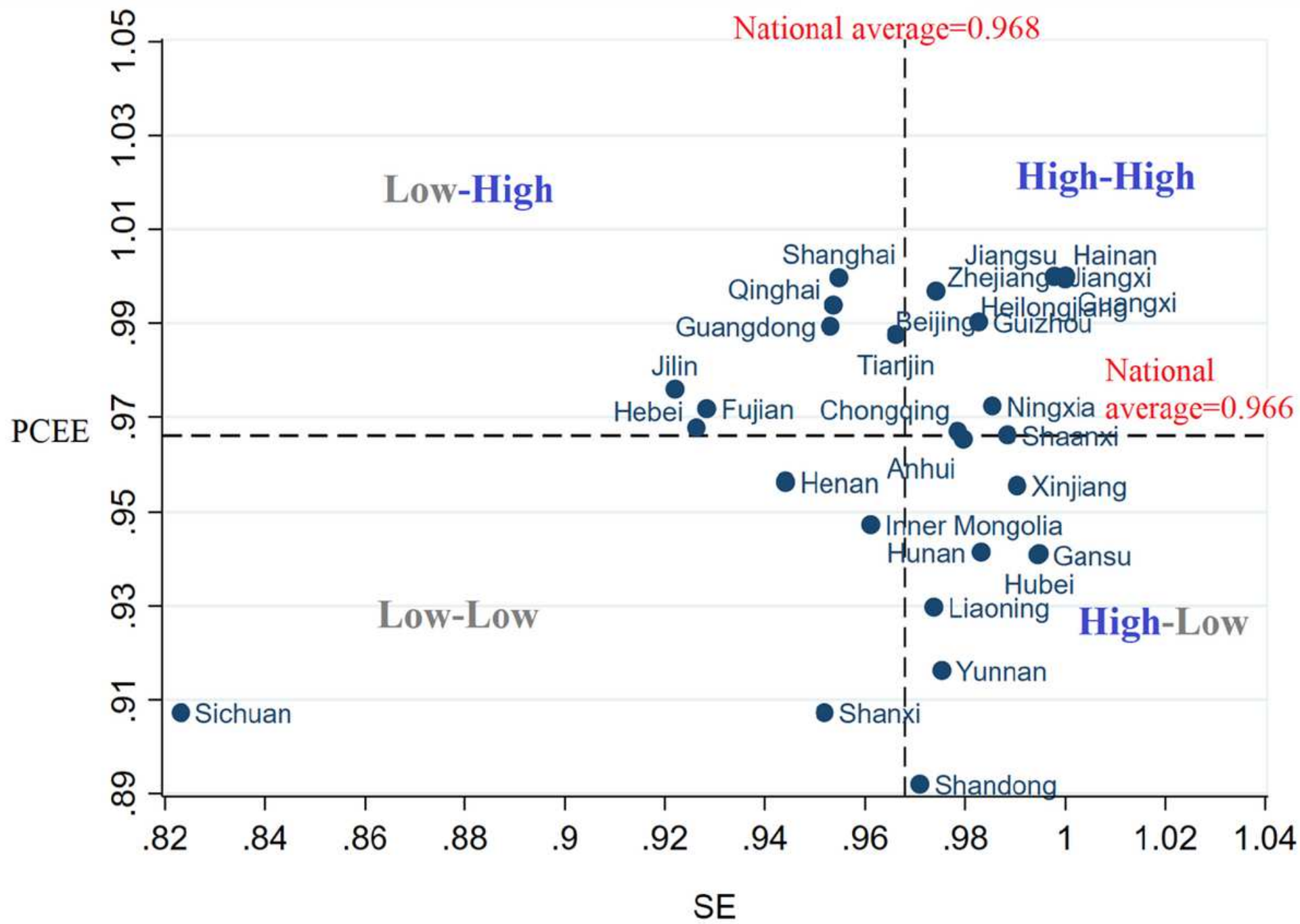

Figure 5

The Decomposition of real $\mathrm{CEECl}$ in different regions 